Portland State University

PDXScholar

Spring 9-3-2013

\title{
Music and Conflict Resolution: Can a Music and Story Centered Workshop Enhance Empathy?
}

Parfait Adegboyé Bassalé

Portland State University

Follow this and additional works at: https://pdxscholar.library.pdx.edu/open_access_etds

Part of the Music Therapy Commons, Other Music Commons, and the Social Psychology and Interaction Commons

Let us know how access to this document benefits you.

\section{Recommended Citation}

Bassalé, Parfait Adegboyé, "Music and Conflict Resolution: Can a Music and Story Centered Workshop Enhance Empathy?" (2013). Dissertations and Theses. Paper 1122.

https://doi.org/10.15760/etd.1122

This Thesis is brought to you for free and open access. It has been accepted for inclusion in Dissertations and Theses by an authorized administrator of PDXScholar. Please contact us if we can make this document more accessible: pdxscholar@pdx.edu. 
Music and Conflict Resolution:

Can a Music and Story Centered Workshop Enhance Empathy?

by

Parfait Adegboyé Bassalé

A thesis submitted in partial fulfillment of the requirements for the degree of

\author{
Master of Arts \\ in \\ Conflict Resolution
}
Thesis Committee:
Robert Gould, Chair
Rachel Cunliffe
Patrick Hiller

\title{
Portland State University \\ 2013
}


C 2013 Parfait Adegboyé Bassalé 


\begin{abstract}
The Story and Song Centered Pedagogy (SSCP) is a workshop that uses songs, stories and reflective questioning to increase empathy. This preliminary study tested the prediction that being exposed to the SSCP would increase empathy using, the Emotional Concern (EC) and Perspective Taking (PT) subscales of the renowned Interpersonal Reactivity Index (IRI) (Davis, 1990). Subjects self-reported their answers to the IRI before and after undergoing the SSCP intervention. Comparing their pre and post intervention results, no statistically significant changes were noticed for the EC and PT scales $(\mathrm{p}$-value $=0.7093$ for $\mathrm{EC} ; \mathrm{p}$-value $=0.6328$ for PT $)$. These results stand in direct tension with the anecdotal evidence gathered from 10 years of action research that shows that the SSCP impacts audiences' ability to empathize. This opens the door for additional research with more rigorous methodology and a larger sample size which will allow for more interpretative analysis. These results also probe the concern about whether the IRI is the most suitable tool to quantitatively measure the empathetic responses caused by the SSCP and evidenced by action research.
\end{abstract}




\section{Dedication}

This work is dedicated to my newborn child, Aushti P. Bassalé. Your birth and coming to this world has renewed my passion and motivation to complete this project. You symbolize the next generation; the many children either already here or yet to come who will inherit the world we leave to you. You remind me of the urgent task at hand: to teach empathy to a critical mass for a more peaceful and loving future.

To you and your peers:

\section{Verse 1:}

You showed me something worth the pain

Something I could not escape

Something my fears could not tame

So I could continue this ride

So my life I could sacrifice

\section{Verse 2:}

You showed me something much more than fame

But yet could heal me from my shame

Something my pride could not claim

So I could keep up with this life

So I could stick around a longer while 


\section{Chorus:}

Time, time, time again

It felt as if it was always the same

(when I could not see)

There was something better than any other gain:

The gift of truth I find in you

You remind me of what love can do

A miracle no one can undo, you are my Jewel

\section{Verse 3:}

You showed me something I cannot explain

Something my dreams dare not imagine

Some' so extreme I could only sing

Love breathing life, it's like a fairytale

You silence the strife in my stormy head 


\section{Acknowledgements}

This project would not have been possible without the spiritual support of my parents, the emotional support of my wife and family. To Rachel Cunlife my advisor who has stuck through thick and thin over the course of these last few years. Your guidance and support has meant a lot and has led this project to places I had not thought of initially. Also, big thanks to Patrick Hiller, for jumping into this ambitious project and providing so much insight and expertise. Special thanks to Solange Bassalé, MS. for your expertise in statistical analysis and help making sense of the results of this study. Finally I must thank Dr. Robert Gould, one of the most inspirational faculty I have worked with. Thanks for your humility, support, heart and commitment to the often not-so rewarding calling of conflict resolution. 
TABLE OF CONTENTS

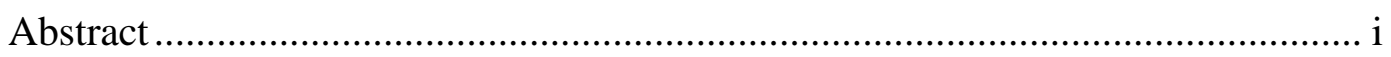

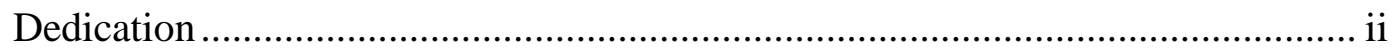

Acknowledgements ................................................................................... iv

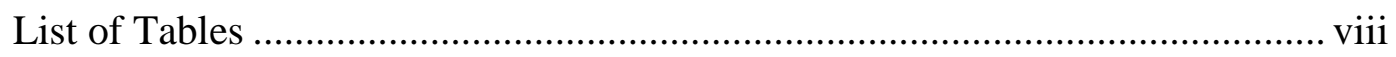

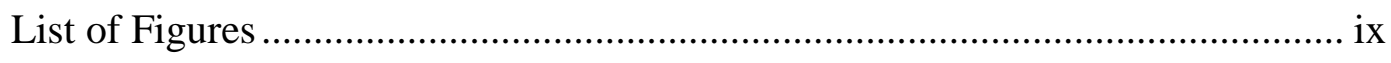

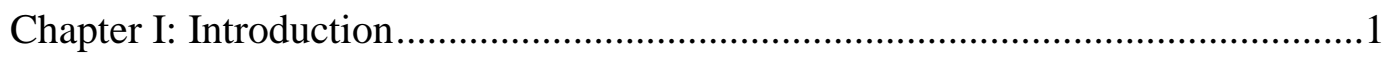

Socio-political Context Informing this Study ……..............................................

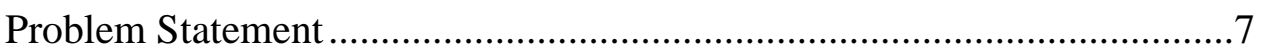

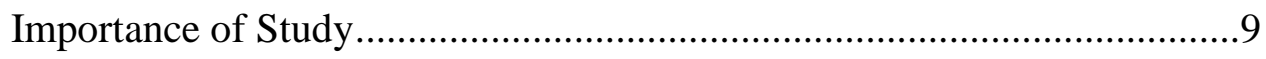

Personal Stance to the Study ………………………..............................10

Research Question .............................................................................12

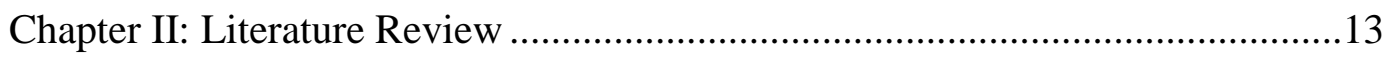

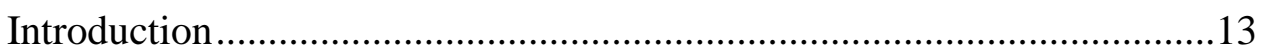

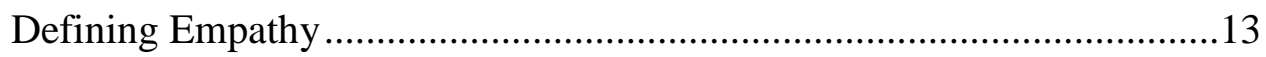

Empathy and Conflict Management …………………………………....15

The Neuroscience of Empathy: Outcomes and Stimuli.............................17

Intrapersonal Outcomes: Personal Distress and Empathic Concern 18

Interpersonal Outcomes: Altruism and Helping Behavior..............23

Self-awareness: a Building-block of Empathy ……………….......24

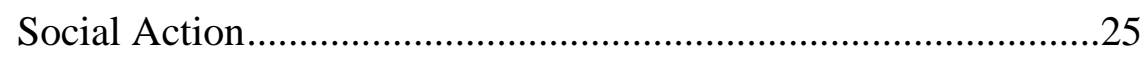

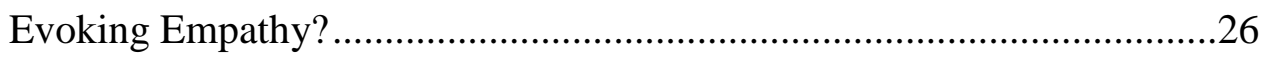

The Influence of Music on Cultural Change and Social Movements26 
The Influence of Music on Mood and Helping Behavior .............28

Music Performance Evoking Empathic Responses .....................31

Can Empathy be Evoked through Songs? ....................................32

How to Systemize the Stimulation of Empathy ..........................33

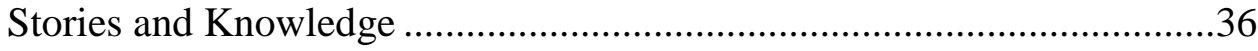

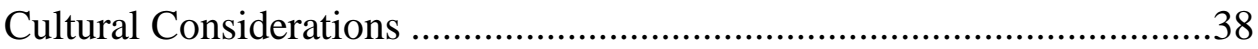

The Story and Song Centered Pedagogy (SSCP) ..................................40

From PowerPoint to Performances ...........................................40

A Student's Story Informing the SSCP ..................................41

A Collective Response to the SSCP .......................................42

A Teacher's Story of Transformation ........................................43

Key Elements of the SSCP .................................................44

Measuring Empathy Quantitatively: The Interpersonal Reactivity Index .45

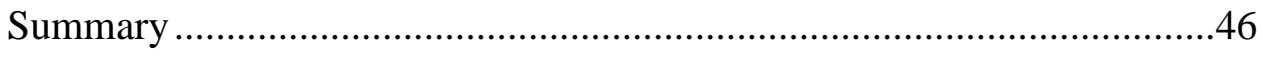

Chapter III: Research Methodology ............................................................49

Rationale for Quantitative Methodology ...........................................49

Theory that Informs Intervention ..................................................49

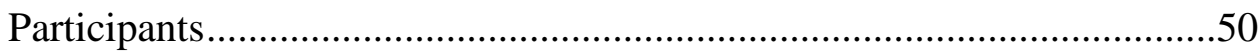

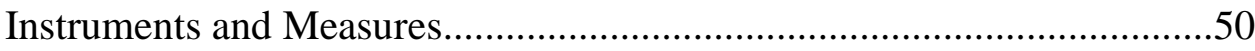

Subscale Inter-correlations and Implications ....................................52

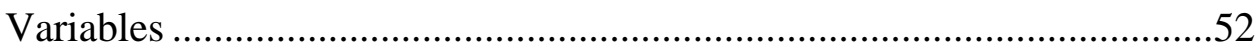

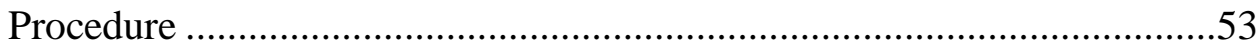

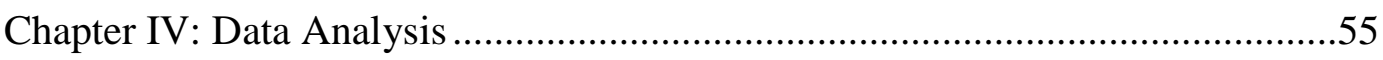




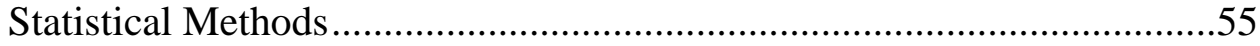

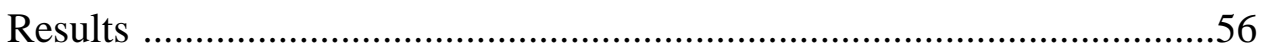

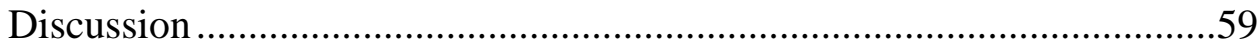

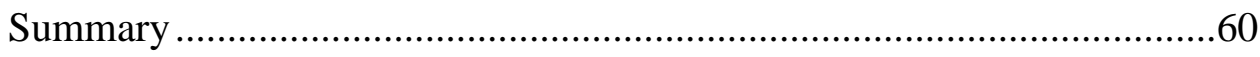

Chapter V: Limitations and Recommendations for Future Research ..................61

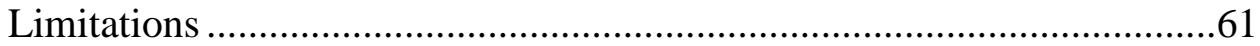

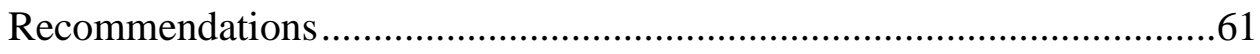

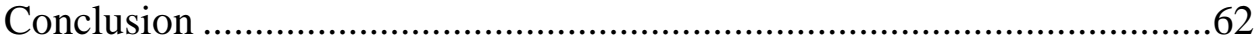

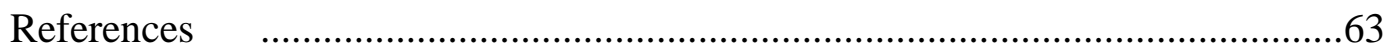

Appendices

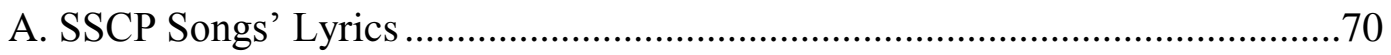

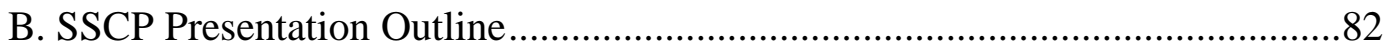

C. Parents Cover Letter and Permission Forms .................................................83

D. SSCP: History, Design and Procedure ....................................................90

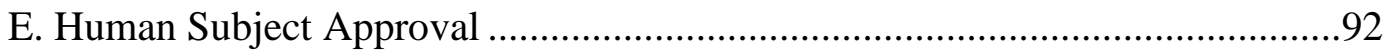




\section{LIST OF TABLES}

Table 1. List of Participants and Valid Surveys ..............................................55

Table 2. Descriptive Statistics of the 4 Subscales.............................................56

Table 3. Correlation between Differences .........................................................59 


\section{LIST OF FIGURES}

Figure 1: Hoffman's $(1984,1987)$ Empathy's Relationships .................................19

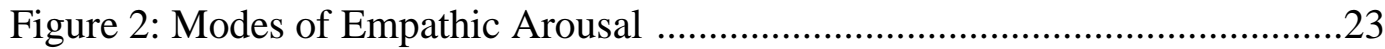




\section{Chapter I: Introduction}

Music permeates various aspects of people's lives. Whether heard through radio stations while driving to work, or through an MP3 player while jogging in the park, or through the speakerphones at a shopping center, or as a background score when watching a movie, music is virtually everywhere, surrounding us as we live life. It helps set and direct our moods. Whether with words or instrumentally, songs accompany our human journey; capture, restate and reinforce our emotional experiences. Music gives a voice to our memories, thoughts and feelings. It allows us to relate to one another beyond our most distinct differences.

Storytelling is also known to achieve similar results. Stories connect people, generations and experiences together. They speak to people's failures, losses, hopes and dreams. Just like songs, they serve as means to formulate ideas, and thoughts. As a form of narrative, storytelling is a vehicle through which meaning is constructed. As such, It gives voice to individual and collective experiences and/or conditions that otherwise would be dismissed, denied or misrepresented (Senehi, 2000). In mediation, it is used to empower players in a conflict situation and to identify needs and oppressive patterns otherwise dormant. In peace building, which is an integral part of conflict management, storytelling plays a critical role in creating shared knowledge and memory and negotiating power relations (Senehi, 2000). In light of their ability to carry and convey meanings and experiences, one can but wonder how effective would a workshop that combined both techniques be in enhancing empathy in an audience?

This research paper sought to evaluate a pedagogical approach that combines songs 
and storytelling in order to enhance empathy. In this introductory chapter, I lay for the reader a foundation for this study and establish its relevance given the current sociopolitical global context. In Chapter 2, I review the academic literature to better understand the role empathy plays within the context of conflict resolution. I then explore its neuroscience which informs us a great deal about the stimuli and processes involved and the outcomes observed when one empathizes. The chapter then explores ways the stimulation of empathy can be systematized in light of the neuroscience, pedagogical and cultural considerations. At the end of the chapter, I introduce The Song and Story Centered Pedagogy (SSCP), a theoretical framework that uses both (songs and stories) to stimulate empathy. Chapter 3 explores an assessment method to measure the effectiveness of the SSCP: the Interpersonal Relationship Index (IRI), a well-known tool designed to measure empathy. In chapter 3 I also describe the methodology employed to test and measure the effects of SSCP on the development of empathy. In chapter 4, I present the findings of the study conducted on a high school student population using the SSCP. The findings are followed by an analysis and discussion about the results. In chapter 5 I address limitations experienced during the study and I make recommendations for future research on this topic.

\section{Socio-Political Context Informing This Study}

The $21^{\text {st }}$ century is a unique time in human history. For the first time humans are interlaced economically, socially and politically through a globalization process that spans over continents (Rifkin, 2009). Geopositional satellites and technologies track the continents and relay audio, video, text, and localized information to billions of people 
almost instantaneously. The logistical infrastructure of modern commerce and trade is becoming nearly seamless. The components of manufactured goods of every kind are made in different countries, shipped and assembled before their consumption in home markets. Automobiles contain thousands of sub-parts from different lands. The energy used for both domestic and industrial purposes: oil, coal, natural gas and uranium are increasingly processed outside native lands and re-imported back. Labor migration has spilled over national boundaries.

Additionally, economic and political systems are so intertwined (Financial systems, World Bank, World Trade Organization, International Criminal Court, United Nations) that a problem, a conflict or a dispute in one part of the world has far reaching consequences for everyone. One example of this interconnectedness is the recession that affected the financial markets in 2009. According to David Robertson (2010): the global financial crisis caused synchronized reductions in the imports and exports of most countries. Modern supply chains, linked by efficient communication systems, quickly brought bad news to markets, consumers and producers. Paralysis in the financial sector suspended trade credits and banking services, leading to immediate reduction in output and shutdowns (p.35).

With this socio-political context of the $21^{\text {st }}$ century, people are coming in contact with one another easily and more frequently. They do so with their cultural identities and biases. More importantly these cultural identities inform their philosophical perspectives on interpersonal communication and conflict management. For instance, Augsburger (1992) in a diagram representing the polarity in responses to perceived wrong doing in 
six different countries, presents the many faces of forgiveness cross-culturally. He explains how in each culture, depending on whether mutual horizontal reconciliation is preferred over vertical acceptance or lateral inclusion, people will forgive differently: Harmony calls for a forgiveness of overlooking; justice for a forgiveness of repentance; solidarity for a forgiveness of ostracism; honor for a forgiveness of repayment; dignity for a forgiveness of principled sacrifice (p. 262)

These cultural differences heighten the stakes in a global context because people frequently project onto others their own knowledge, feelings, opinions, attitudes, judgments, behaviors and desires (Decety \& Ickes, 2009, p.45). This process of projection is considered by some academics as the most common approach to formulating knowledge about a person in the absence of information about that person (p.44). Several experimental studies since the 1930s have helped confirm the hypothesis that people who engage in a particular behavior tend to estimate that the behavior is more prevalent than those who do not engage in the behavior. For instance Katz \& Allport (1931) found that students who cheat on an exam are more likely to think that others cheat as well. Goldings (1954) found that the extent to which one perceives others to be happy is contingent upon how happy one feels. Bennet and Hibberd (1986) also found that victims of crime make a higher estimate of the incidence of crimes than those who have not been victims. O’Mahomy (1984) argues that the use of projection increases the less one knows about the person with whom one is communicating. While assumptions are necessary for engaging in any type of interpersonal communication, their use without contextual nuance and cultural insight can be dangerous. To assume without suspension of judgment 
conditions one to viewing the world in binary terms: right and wrong, good and evil, with us, against us. Without advocating for relativism it is fair to recognize that within the global context described up to this point, such reductionist outlooks on differences can escalate disagreements and conflicts.

In addition to cultural differences, and to the propensity to project, people's habitually unhealthy approaches to conflict resolution also heighten the risks of conflict escalation. According to Augsburger (1992) people's methods of resolving disputes and conflicts, especially major ones, are inadequate and ineffective. Cultural traditions often condition most people to engage conflicts with old patterns of "either-or thinking", argumentative or oppositional disputations, and competitive and win-lose forms of resolution (p. 5).

Also, media culture, including music, movies, video games, magazines, debates on TV, polarizing public figures, newspapers, etc play an important role in shaping societal norms as they relate to interpersonal communication and conflict management. In most cases, these norms by promoting poor active listening skills, are counter-examples of the empathetic and transformational conflict management approach which champions active listening and understanding. They promote "othering", division and the vilification of people who hold views that are different from one's own. To quote Cornel West (2004) in his analysis of the effect of corporate marketing on democracy matters, he says: The incessant media bombardment of images (of salacious bodies and mindless violence) on TV and in movies and music convinces many young people that the culture of gratification - a quest for insatiable pleasure, endless titillation, and sexual stimulation- is 
the only way of being human. Democratic ideas of making the world more just, or striving to be a decent and compassionate person, are easily lost or overlooked (p. 175).

One additional challenge for humanity in this $21^{\text {st }}$ century is the unprecedented rise of technology and the use of the Internet to connect people. Communication devices and social media platforms although in some cases, allowing us to connect more rapidly with one another regardless of geographical distances, and helping harness support for democratic movements in certain parts of the world (e.g. The Arab spring), have brought about new challenges to interpersonal relationships. They have shifted the pendulum from an other-centered relational model to a more self-focused and narcissist culture. Some have referred to this phenomenon as the "me-generation" (Manney (2008), Marsden, (2009)). The impersonal nature of these technological advances now provides multiple outlets for narcissistic behavior. One has at the tips of our thumbs ways to feed the addictive needs to feel important and to be at the center of the world (Marsden, 2009). As a result consensus building is harder, respectful debates in the public sphere are rarer. Anyone through anonymous screen names can slur and disrespect and demonize others with a different opinion. Or yet, anyone can start a blog or website and polarize a conversation without a sense of accountability to the larger community.

This phenomenon has grown into a new form of violence known as "cyber bullying". According to the Cyberbullying Research Center, and the I-SAFE foundation, about half of young people have experienced some sort of cyberbullying while 10 to 25 percent experience it regularly (Bullying statistics, 2009). As explained by Willard (2003), the cyber world provides enabling factors to cyber-bullying such as anonymity, 
false identity and the absence of visual feedback of the pain inflicted. By creating a fragmentation of communities, the cyber world allows individuals to escape the necessity of getting along.

However, it is important to note that the cyber world and new technologies can help support democratic processes and disaster relief in new ways. For instance, by providing an avenue for protesters to communicate with the rest of the world via text messaging and Youtube during the "Arab Spring", activists from Tunisia and Egypt were able to harness international support. Similarly, not for profit organizations involved in post disaster relief in places like Haiti, were able to communicate more quickly to an international audience, the scope of the damages and needs at hand. Through text messaging, these organizations could receive donations fairly quickly to help finance their efforts. These positive examples of the use of technology to fuel global empathy towards specific causes, reminds us that technological advances are not inherently bad. They have the potential to further empathy or to hinder human connection.

\section{Problem Statement}

Manney (2008) argued that as our world grows more interconnected and technological in the $21^{\text {st }}$ century, the role of empathy becomes more important than before. In light of the background provided, there is indeed a pressing need to help people develop effective conflict resolution skills on a global scale. This is important if we wish to halt the cycles of violence (both emotional and physical) and to eradicate the processes of enmification.

The next logical question is to know how the empathetic and transformational 
conflict management model that emphasizes the identification of needs underneath positions, can be taught effectively in a cross cultural fashion to youth; the next generation of decision makers? In this study I posit that skillful and methodical songwriting coupled with storytelling can help achieve this goal.

Music is the first articulation of this pedagogy because of its ability to convey emotions that are shared cross-culturally despite language barriers. Levitin (2008) demonstrated that the history of humanity has been shaped through six types of songs: friendship, joy, comfort, knowledge, religion and love (p. 40). Additionally, songs can serve as abstractions thereby allowing a songwriter to express a general idea without needing to deal with specificities. Also, by virtue of being artistic expressions, songs are often perceived as less threatening, therefore, providing a platform for artists to influence their audiences through lyrics. Several studies that will be explored in more depth in the literature review have shown that music has the potential to influence mood, feelings and thoughts (Huda, \& Ganser, 2010). Additional studies have proved that pro-social songs influence helping behavior (Greitnemeyer, 2009).

Storytelling is the second articulation of my pedagogy for a number of reasons. As suggested by Schank and Abelson (1995) stories are essential to the way humans create meaning and store knowledge. We store facts as pieces of bigger narratives; we resonate with stories that remind us of stories we have heard or have composed ourselves and only remember these stories or the ones that are in dissonance with the ones we've always heard. Moreover, stories are a safe medium by which we can connect with the feared “other”. For instance by reading Goldman's Memoirs of a Geisha, one can feel for 
a geisha's existence while bypassing the painful process of being sold into human slavery and training to be a geisha oneself. One can achieve this without even going through the cultural and/or linguistic embarrassment of having to speak to a geisha (Manney, 2008). Storytelling seems to operate as a catalyst for a virtual experience that produces similar results as a physical experience. In addition, by providing real life context for learning, storytelling makes instruction less theoretical for an audience. When an audience is given the opportunity to apply their learning in ways that can affect the outcome of a story, it provides purpose for the learning. These characteristics of storytelling make it an important tool for teaching new sets of skills about the human experience.

\section{Importance of Study}

Having established that the $21^{\text {st }}$ century has witnessed the emergence of a global world stage that brings into close contact polarizing and often misunderstood worldviews, I propose that empathy is a key skill that must be taught within the context of conflict prevention and conflict resolution and used in conjunction with intellectual and critical thought.

This study is important to such agenda because it explores a pedagogical approach that tries to help evoke empathy by way of narratives and implicit modeling of behaviors and skills necessary for empathy. Implicit modes of instruction bypass some known barriers to interpersonal communication such as accents, tonality, misinterpretation, defensiveness etc. In addition they are as effective as explicit modes of instruction. In a study designed to test whether implicit instruction versus explicit instruction was more effective in teaching everyday skills to individuals with dementia, Hulstijn, Kessels and 
Tilborg (2011) concluded that both approaches were effective in teaching new skills with similar rate of learning regardless of whether implicit or explicit learning techniques are used. The study consisted of training participants at two daily tasks (using a microwave oven and a coffee machine) that were novel to all participants. Each participant learned both tasks, one by implicit learning method (modeling) and the other using an explicit learning method (providing cues).

Secondly, this study roots its intended outcomes in current trends observed in educational circles. Private, public and international schools 'curricula are emphasizing the instruction of global competence which includes dimensions of self and peer awareness and global perspective taking (Asia Society, 2013). This overlap of intended outcomes positions this pedagogy as an additional resource in teachers' toolboxes in classrooms across the globe.

At a personal level, this study is very important because it is the culmination of a lifetime of work and vision. It contributes to my conviction that music and songwriting have their place as educational pedagogies in classrooms. These techniques have been used to carry and support the message of social movements across history and are currently being used to shape and alter culture. To bring these tools into the classroom is an effective and proactive initiative that can counter the negative effect of popular culture on the youth population.

\section{Personal Stance to the Study}

As a 12 year old immigrant from Benin Republic living in the Senegal Republic, I was introduced to southern French rap music. The genre is made by looping one or two melodic patterns, often borrowed from western and/or oriental classical pieces (generally 
in the minor key), and combining these with an upbeat tempo. The artist then proceeds with the poetic narration of a story with the intent to evoke emotion in the listener. This music resonated with me because of the nature of the composition and the performance. By means of rhymes, sounds, metaphors, and the emotions embedded in each song that I enjoyed, composers made me care enough about a social issue, that I would take a stand and was made to empathize with the experiences of the subjects in their narratives. I, too, soon began composing music as a means to express my own pain and to evoke the empathy of my listeners. I followed the same methodology, using storytelling and melancholy instrumentals in my songs. Sixteen years later, as I grew as an artist, I learned the guitar and began to sing, I pondered how best I could compose songs that would enact social change by teaching and enhancing the skill of empathizing to my audience, so as to help bring about a more peaceful world.

I enrolled in the Conflict Resolution program at Portland State University, and throughout my studies wondered how the conflict resolution skills I was learning could be taught via musical compositions. I conducted brief studies in my classes and learned that throughout history, music has been used as a support to social movements, and has played a significant physiological and psychological role in human development (Johnston, 2010). The literature stressed the importance of including music in the toolkit of the conflict resolution practitioner because of its intrinsic ability to alter emotions (Johnston, 2010). However the literature did not provide much information about strategies and methodologies.

The closest application of music to emotional and social health has been through 
music therapy. As described by the American Music Therapy Association, music therapy is a well-established clinical and evidence based use of music interventions to address individualized goals for physical, emotional, cognitive and social needs within a therapeutic relationship (AMTA, 2006). It is considered an effective intervention for maintaining and improving active involvement, social, emotional and cognitive skills, and for decreasing behavioral problems with individuals with dementias and Alzheimer (Brotons, Koger, \& Pickett-Cooper, 1997). It has also proved to be an effective anxiolytic treatment by preventing significant increases in subjective anxiety, heart rate and systolic blood pressure (Knight \& Richard, 2001).

With such powerful benefits, and evidence on the anxiety reducing effect of music on patients undergoing surgery, it is important to explore its possibilities in the field of conflict management.

\section{Research Question}

This study intended to provide academic evidence to help support peace practitioners who wish to use songs to increase empathy. In other words, the study sought to answer the question: can a quantitative methodology confirm the anecdotal evidence informed by action research, that a song-centered workshop enhances an audience's empathy?

To help answer this question, it was important to first, gain a deeper understanding of empathy as a construct. Hence, I organized the next chapter into three guiding questions: Why is Empathy important to conflict resolution? How does empathy work? How can empathy be taught? 


\section{Chapter II: Literature Review}

\section{Introduction}

In this chapter I survey the existing literature on empathy. My aim is to first develop an understanding of the construct, its relationship to conflict resolution for a better assessment of its desirability in the field of Conflict Resolution and culture as a whole. Next, I dive into its neuroscience in order to better grasp its stimuli, processes and outcomes. I then explore music, stories and their ability to affect mood and stimulate empathy. Next, I look at pedagogical, theoretical and cultural considerations when one attempts to systematize the instruction of empathy. This I hope will lay a good foundation for introducing the Story and Song Centered Pedagogy (SSCP); a workshop centered on songs and stories to help enhance empathy in classrooms. Finally, I conclude the chapter with the review of the Interpersonal Relational Index, an empathy measurement tool.

\section{Defining empathy}

In the literature, empathy is generally defined as one's ability to understand and share another's emotional state (de Wied, Branje \& Meeus, 2007). Also referred to as “other-centered emotion” it describes one's capacity to imagine and feel another person's situation (Rumble, 2009; Van Lange \& Parks, 2010). These general definitions seem to imply two components of empathy: a cognitive process and an affective process. Historically, there was a view of empathy that described it solely in terms of its cognitive process. One prominent voice of this view was Kohler (1929) who argued that empathy was the understanding of others' feelings rather than a sharing of them. With this view, as explains Davis (2006) "Understanding other people, as opposed to feeling what they felt, 
could be accomplished merely by viewing and interpreting the actor's actions, movements, and physical cues." the process of interpretation being that cognitive process that leads to an affective response (p.6). After 1950, a more emotional emphasis to defining empathy surfaced (Davis). Empathy began to be described as a purely affective and reactive process; a neurological response to external stimuli (Urbain, 2008).

According to Davis (2006), these two views were at odds with one another because on one end the purely affective view was defining empathy strictly in terms of an outcome: affective response. While on the other end, the cognitive process view, was concerned with empathy as a process.

After a long debate over these philosophical views of empathy, scholars in recent years have come to agree that empathy is a multidimensional phenomenon (Devoldre, Davis, Verhofstadt \& Buysse, 2010). The general consensus is that empathy involves two key processes: a cognitive process (simple association of self with the other, or complex perspective taking) and an affective process (deWied et al., 2007). With this consensus in mind, I propose the following definitions of empathy and perspective taking: Empathy: A subject's emotional experience and conscious response by means of cognitive processing (perspective taking) of the unconscious mirroring of feelings and thoughts of another person's experience.

Perspective taking: The process of cognitively seeking to understand the context surrounding another person's experience.

This definition can be summarized by a quote by Gerdes, Lietz, and Segal, (2011): "Empathy is not only a condition, it is an action motivated by affect and cognition." (p. 
123). This definition characterizes empathy as a symbiotic process and represents the integration of two philosophical views of empathy that conflicted over time. In the next section, I look at various outcomes associated with these processes. Does one observe different outcomes depending on whether one uses cognitive empathy or affective empathy? Can one engage in one process without the other?

\section{Empathy and Conflict Management}

A good understanding of the relationship between empathy and conflict management helps better assess the desirability of empathy in culture. To establish a relevant relationship between empathy and conflict and crisis management, we must analyze the particularities of human relationships and identify the role empathy plays within them. Rumble, Van Lange and Parks, (2009) established that human relationships are universally guided by the norm of reciprocity. They affirm that this reactive and retaliatory norm encourages conflict escalation. It increases non-collaborative actions when individuals intentionally or unintentionally make non-cooperative choices. In a similar study, using the Tit for Tat illustration, Van Lange and Parks (2009) posit that empathy-motivated actions effectively de-escalate the non-cooperative pattern in human relations. Urbain (2008), suggests that an relationships suggesting that Empathy is a fundamental node in human "relatedness" and a "binding" force between people.

One common obstacle to effective communication that often leads to conflict is the phenomenon known as "noise". "Noise" occurs when a behavior is mis-communicated or mis-understood due to external factors that put a cloud of uncertainty on someone's intentions or actions: for example, when one arrives later than intended for a meeting due 
to an unusual traffic jam. Rumble, Van Lange \& Parks (2009) study was designed to test whether empathy can motivate generous behavior, which should help to overcome negative noise in social dilemmas. The study was also interested in how empathy affects behavioral reactions to intentionally non-cooperative others.

The study also manipulated empathy following Batson's procedure (e.g.,Batson \& Ahmad, 2001; Batson \& Moran, 1999). This method focuses on three conditions: High empathy, low empathy, and no communication. Prior to the social dilemma task, participants in the two empathy conditions were told of the misfortune of another person, and were instructed to imagine the other person's situation (high empathy) or take a detached, objective perspective (low empathy). In the "no-communication" condition, participants were not told of the other person's problem. The authors concluded that empathy increased cooperative behavior and was an effective tool for coping with misinterpreted behaviors (Rumble, Van Lange \& Parks, 2009).

Certainly one of the most important findings that testify to the power of empathy to influence human interactions is the Behavioral Influence Stairway Model (BISM). Used and honed by Law enforcement negotiators over thirty years, this model has proved to be highly effective in rapidly resolving crisis without the use of violence (Vecchi, 2009). It comprises four stages: Active Listening, Empathy, Rapport and Influence. In his articulation of the model, Vecchi (2009) describes empathy as "a natural by-product of effective active listening. Empathy implies an identification with and understanding of another's situation, feelings and motives" (p. 4). Vecchi's view of empathy in the BISM model points us to the importance of processes leading up to building rapport and 
influence. Vecchi (2009) goes on and explains the importance of intentionality in the process of empathizing. He stresses the critical role of tone over content. According to Vecchi (2009), the perception of one's attempt to understand the object forms the building blocks for rapport which helps de-escalate the crisis and conflict (p. 4).

In conclusion, one can see that empathy and the perception of empathy can transform the dynamic of ambiguous social situations that could escalate otherwise. Empathy can also halt the reactionary and retaliatory patterns in human interaction by deepening mutual understanding for more cooperative negotiation. This is in line with the goals of conflict management which seeks to de-escalate conflicts and move stakeholders towards mutually beneficial and productive outcomes without sacrificing justice and safety (Lederach, 1996). If empathy is that vehicle that helps remove "noise", and incentivize cooperation, then, it is important to understand how it is triggered and the full scope of the outcomes it produces. Already from the studies in this section, we learned that there is an active cognitive effort (imagine the other person's situation, identify with the other person's feelings) required to empathize. The next section will further investigate the neuroscience of empathy which will help formulate a working definition.

\section{The Neuroscience of Empathy: Outcomes and Stimuli.}

The literature on this topic suggests two types of outcomes: intrapersonal and interpersonal. While these outcomes have differentiable traits, they often happen concurrently. Intrapersonal outcomes happen internally and are not always visible even to a kin observer. They lead to either personal distress or to empathic concern. Personal distress is commonly defined as one's tendency to experience distress and/or discomfort 
when witnessing another person's distress (Davis, 1983). Empathic concern on the other end is defined as one's tendency to feel sympathy and/or concern for others in negative situations (Davis, 1983). The former, channels one's emotional response to the self, while the later directs such response to the person being observed.

Interpersonal outcomes on the other end are visible externally and fall under two categories: altruism or helping behavior. To describe these constructs, I will use Batson (1991)'s definition. He suggests that although the visible outcomes of altruism and helping behavior might be identical, it's the motivating intent that differentiates them. He asserts that when an act has no components of selfish motivation such as feelings of pride, avoidance of internal and/or social punishment, such an act can be characterized as purely altruistic. Anything else he describes as the type of helping one does to either alleviate one's own feeling of distress, or avoid social and/or personal punishment that results from not helping someone in need.

In an ideal world, one would desire empathic concern and helping behavioral as the optimal intrapersonal and interpersonal responses to empathy. However the reality is such that it is nearly impossible to observe these responses in perfect isolation. My goal while reviewing the literature was to identify processes that shift the balance a bit more towards these desired outcomes, in order to design an intervention most likely to produce them in an audience.

Intrapersonal Outcomes: Personal Distress and Empathic Concern. Personal Distress and Empathic Concern are both internal affective responses of empathy. As indicated in Figure 1: Hoffman's (1984, 1987) Empathy’s relationships (p. 31), thee two 
constructs respond oppositely to cognitive activity / perspective taking. Empathic Concern increases as one engages cognitively to understand another person's distress, whereas, Personal Distress decreases during such cognitive activity. This is almost as if there is a shift from self to the other that takes place as one engages in perspective taking.

Figure 1: Hoffman’s (1984, 1987) Empathy’s relationships

\section{Hoffman $(1984,1987)$ Empathy's relationships}

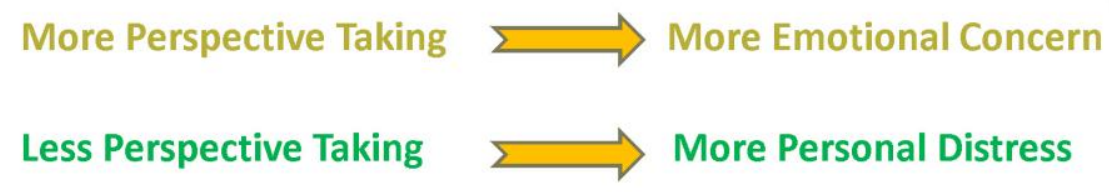

According to Hoffman $(1984,1987)$, one's level of cognitive functioning is the single most important indicator of the type of affective outcome one experiences when empathizing. The more complex the cognitive engagement: role taking or perspective taking, the more empathic concern one experiences. However, the less one engages cognitively and/or, the more one reacts in an automated manner, the more personal distress one experiences. Each one of these intrapersonal experiences in turn, respectively influences the types of interpersonal responses one exhibits: altruistic behavior or helping behavior. Cognitive processes evolve from childhood to adulthood and affect one's empathizing as suggests the developmental psychologist Hoffman $(1984,1987)$.

In his work, Hoffman $(1984,1987)$ found that as an individual develops cognitively, he or she in addition to automatic neurobiological responses to situations can 
engage in more nuanced processing of the cues observed. By so doing, his or her responses become less self-serving (to alleviate personal distress) and more directed towards the person and situation being observed (out of empathic concern).

The automatic neurobiological responses responsible for causing personal distress are referred to as the primary modes of empathic arousal. They are available in early years (Hoffman, 1984, 1987) and comprise the Primary circular reaction and the motor mimicry. The Primary circular reaction, is characterized by the tendency babies have to cry when they hear other babies cry. The motor mimicry is a two steps process whereby an observer automatically imitates a person (facial and posture) and by so doing generates internal kinesthetic cues that tend to create in the observer a comparable emotional reaction as experienced by the person being observed. The discovery of mirror neurons in recent years, supports Hoffman's explanation of these primary modes of empathic arousal. Iaccoboni (2009) explains:

Mirror neurons provide an unreflective, automatic simulation or inner imitation, of the facial expressions of other people. Simultaneously, mirror neurons send signals to the emotional centers located in the limbic system of the brain through the insula. The neural activity in the limbic system triggered by these signals from mirror neurons allows us to feel the emotions associated with the observed facial expressions (p. 111-112).

It is important to note that these modes of arousal are not restricted to childhood but also operate automatically throughout adulthood.

More advanced forms of empathic arousal, which become available as an individual develops cognitively, comprise classical conditioning, direct association, language 
mediated association and role taking. For review of these forms in depth, refer to Hoffman's work $(1984,1987)$. For the sake of this study, I will focus on the language mediated association and role taking modes of arousal. The language mediated association is a cognitive process by which an observer makes a direct association between a person or a situation being observed and his or her past experiences by means of language and semantic triggers. For example the person being observed could verbally state "I am afraid" or describe the situation "I flunked my exam" and the meaning expressed symbolically through these words triggers associations with comparable feelings and experiences stored semantically in the observer's memory. Because narratives rely heavily on semantic to convey symbolism and meaning, Hoffman's model provides a framework for using descriptive semantic to trigger empathic response in listeners. Role taking, is considered the most cognitively advanced mode. It requires the observer to deliberately imagine how himself/ herself would feel if placed in the circumstances being observed. By so doing, he or she triggers associations with past experiences with similar circumstances. According to Hoffman, these modes of arousal, whether primary or advanced, can occur concurrently. What dictates their trigger depends heavily on the situation. With strong expressive cues, mimicry is more prevalent. Clear situational cues may increase the likelihood of conditioning and/or direct association. Significant semantic content may prone language-mediated associations.

Hoffman is not alone in his analysis of various modes of empathic arousal. Eisenberg and her colleagues (Eisengber, Fabes, Schaller, Carlo, Miller, 1991) have also identified other primary modes of arousal such as conditioning and labeling. Like 
Hoffman, they have categorized these empathic triggers as lower and/or primary modes of arousal because they operate automatically without conscious direction by the observer. Primary modes of arousal generate mirror responses whereby an observer experiences affective states that match or reproduce those of another person (Staub, 1987). Higher levels of cognitive modes of arousal such as classical conditioning, direct association, language-mediated association and role taking (perspective-taking) require a deliberate effort by the observer and lead to an other-centered affective response (Hoffman, 1984; 1987). Eisenberg, Shea et al.(1991) believe the cognitive activity is what transforms the automatic, neurobiological parallel affective response from selfcentered to other-centered.

Modes of empathic arousal influence the types of intrapersonal empathic response. The more primary and automatic the arousal, the more personal distress one experiences. The more cognitively advanced the arousal, the more empathic concern one observes. (See Figure 2: Modes of empathic arousal, p.35). These two types of intrapersonal outcomes, in turn, influence the types of interpersonal responses one witnesses: Altruism and Helping behavior. In the next section I explore the difference between altruism and helping behavior and how they get triggered. 
Figure 2: Modes of Empathic Arousal

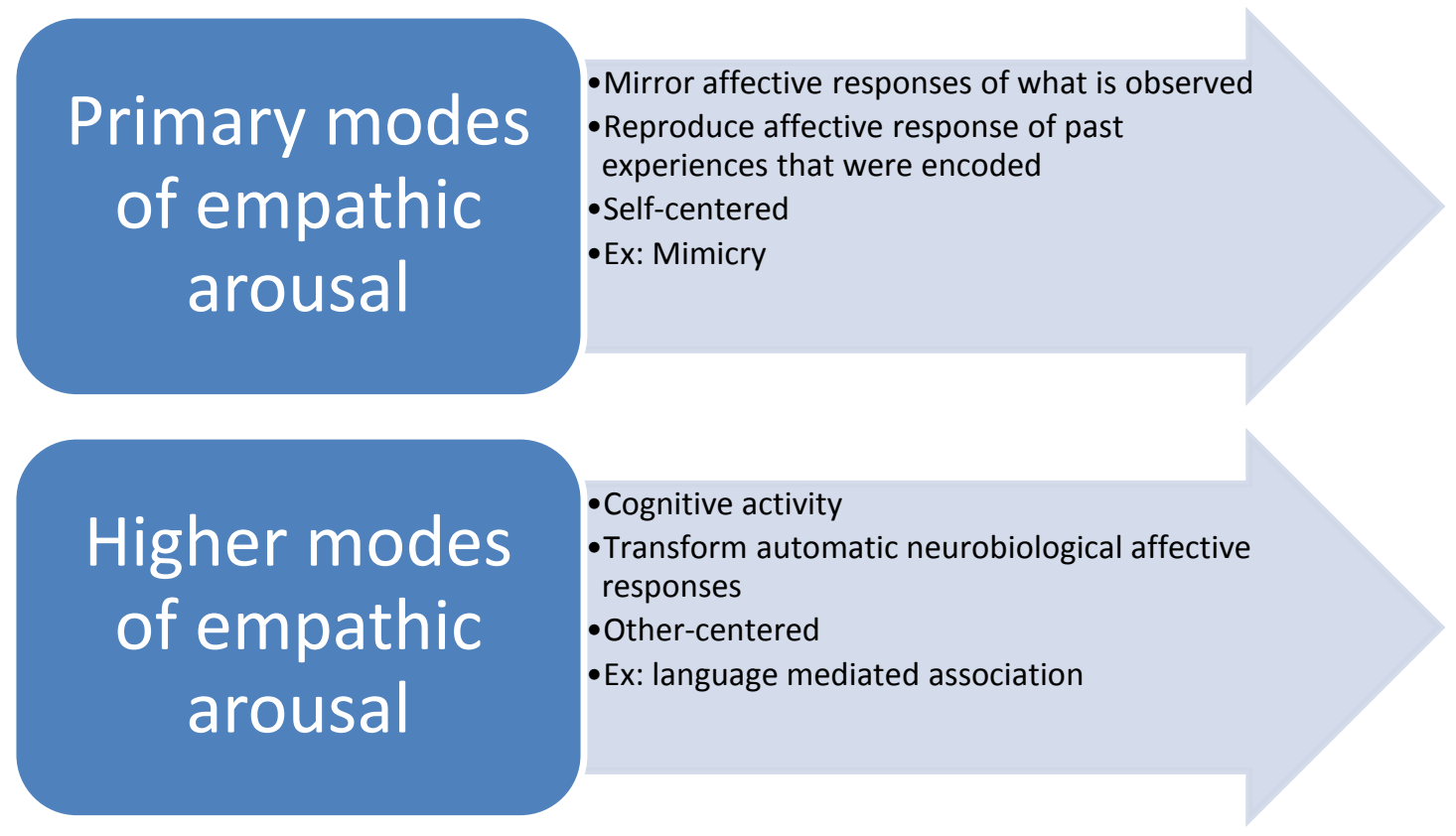

Interpersonal Outcomes: Altruism and Helping Behavior. To define and

differentiate the constructs of altruism and helping behavior, I will use Batson (1991)'s approach. He distinguishes altruism and helping behavior based on the type of motivation driving the act. Batson (1991) asserts that when an act has no components of selfish motivation such as feelings of pride, avoidance of internal and/or social punishment, such an act can be characterized as purely altruistic. Any other motivation falls under the “Helping” category. Based on Batson's definition, Altruism seem to be an extension of empathic concern.

Batson's (1991) experimental research has shown that when individuals are experiencing empathic concern, no amount of difficulty or threat to self, thwarts the willingness to perform the compassionate act. Whereas when the individual is motivated by personal distress, the higher the difficulty, the less likely the compassionate act. 
Batson's work is very critical for the design of my pedagogy. His experiments reveal that when an observer is predominantly driven by empathic concern, this trumps fears and concerns for hurt and/or comfort. Difficulty to help is no longer an obstacle to assisting a person in distress. The altruistic response is an optimal outcome. The reason for this is that in most cases of conflict, parties' perception of unbearable level of difficulty and threat to self are what inhibit their ability to empathize. By evoking a sense of similarity and connection, and by engaging the audience into perspective taking, it enables it to exhibit altruistic behavior as defined by Batson.

As a summary, cognitive activity through perspective taking is a major trigger for empathic concern which in turn helps produce altruism. In the next section I will be looking at self - awareness which plays an important role in perspective taking.

Self-Awareness: a Building-Block of Empathy. Part of Batson's work has also shown that developmentally, individuals become capable of more complex cognitive processes such as perspective taking as their sense of self as different from others increases. Having already established how these more complex cognitive processes (perspective taking, association etc) cause more empathic concern, I infer in light of Batson's work that self- awareness is a building block of empathy. It is important to note that self-awareness is not systematically associated with one engaging in perspective taking. In fact, the research has shown that in most cases where empathic concern was most observed as a result of direct perspective taking, these were scenarios in which subjects had to be given instructions to first imagine themselves in distress then imagine how it would feel for the person in distress being observed. This is noteworthy and 
consistent with Jones and Nisbett (1972)'s assertion that people take a different perspective when acting than when observing others act. When people perform an act, they are well aware of the environmental pressures that conspire to make them behave as they do. However when they watch others act, they tend to attribute their actions to their personalities and desires and to discount any situational pressures that motivate them to behave as they do. Research on how to alter mental patterns that cause these double standards of using perspective for self but incrimination for others led me to the work of Siegel.

Siegel (2004) argues that self-understanding is a way to altering mental models that the brain has learned to shape automatically without conscious attention. He suggests that through reflection one can deepen self-understanding. Conscious processing of memories, rigid mental states and automatic responses opens the door to conscious awareness, which brings the possibility of change. Siegel's work is very valuable to this research. It not only informs us that self-awareness is a building block for empathy. But it also provides us with the technique to increase self-awareness and modify mental models by means of self-reflection; all of which can be modeled by songs and stories, and/or triggered by questions.

Social Action. The previous discussion about action as a result of empathy has been further developed by Gerdes, Lietz, and Segal (2011). They argue that the full extent of empathy is not limited to a feeling. Empathy culminates with one's decision about what to do with and how to channel one's aroused empathic feelings and thoughts. On the basis of multi-disciplinary approaches and recent discoveries in neuroscience, 
social science and social work practice, they have developed a framework of empathy that consists of three dimensions: (1) the affective response to another's emotions and actions, (2) the cognitive processing of one's affective response and the other person's perspective, and (3) the conscious decision making to take empathic action. According to Gerdes, Lietz and Segal, the affective response identifies the involuntary physical reactions triggered by external stimuli. The cognitive processing of the unconscious mirrored feelings and intentions is voluntary and requires mental skills to interpret the physiological sensations as well as the thoughts that are triggered by mirrored experiences. This processing includes self-awareness, perspective taking and emotional regulation. The third component of conscious decision making draws from social work and stresses empathic action. Empathic action requires that one moves beyond affective response and cognitive processing toward use of behavioral health values and knowledge to inform actions and choices (Segal, 2007, in press).

Evoking Empathy? Thus far we have learned that empathy is an affective and cognitive response to external stimuli that translate into action meant to alleviate someone else's distress. In this section, as I build a path to a pedagogical framework that will help systematize the stimulation of empathy, I look at music and its historical influence on human mood and social movements, to derive ways it can effectively support this framework. Lastly, I look at storytelling within the context of instructional pedagogy to help inform the story and song centered pedagogy.

The Influence of Music on Cultural Change and Social Movements.

Whether through cultural change or social movements, music and songs are central in 
shaping modern cultures. Music as a carrier of past traditions bears images and symbols to help frame present reality. It does so by being open ended, suggestive in the way it encourages action through symbolic representation (Eyerman \& Jamison, 1998). In the United States cultural expression and culture experiences have served to define the country's national identity. American social movements through the articulation of their praxis in songs, dance and culture (abolitionist movement, civil right movement, 1960s movements) have periodically challenged the "power elites" and their notions of culture and consequently have created an alternative kind of popular culture (Eyerman \& Jamison). According to Eyerman (2002), the sociologist and African-American activist W.E.B. Du Bois (1868-1963) believed arts should represent the best possible image of blacks in order to counter the negative stereotype present in dominant popular culture. This instrumentalist view of art is obvious in the music used during the American Civil Right movement also referred to as the singing movement. The capacity of songs to connect the collective by linking past, present and future experiences creates a sense of empathic belonging. Based on his own experience explained in The Souls of Black Folk (1903); Du Bois notes that even a relatively distant observer can share in the collective memory articulated through a song. Du Bois as a northerner college educated intellectual was able to experience an empathic belonging when he first heard the "sorrow songs" that emerged from the times of slavery. Eyerman (2002) notes in this example the role the "Sorrows songs" played in allowing Du Bois to identify with a group he will never meet face-to face. Through the bridge of music, the praxis of the resistance had found a new voice in a contemporary context. It has found continuity and a way to express its motto and grief without the censorship of dominant culture. 
In the shadow of songs such as "We shall overcome" considered to be the American Civil's Right movement anthem, new musical genres of public protest have surfaced in the 1980s. The most popular one is Hip Hop whose central thrust as noted by Cornel West (2004) is "the criticism against the dogma of free-market fundamentalism and the increasing wealth inequality all around the world that the slavish devotion to the dogma has produced" (p.178). By means of poetry, rhymes and storytelling Hip Hop was a vehicle by which artists would decry socio-economic conditions and raise popular awareness about the plight of the dis-franchised. The movement grew in popularity and reached youth culture outside the USA. Hip hop is virtually in every continent today as an expressive form of public protest.

However as West (2004) notes, in recent years the mainstream Hip Hop movement is ironically viewed as a nihilistic, macho, violent and "bling-bling" phenomenon when in fact its originating impulse was a fierce disgust with the hypocrisies of adult culture. Its goal was to bring about a more equitable society by means of denunciation. This irony is relevant to our study because the free-market fundamentalism phenomenon described by West, has capitalized on the instrumentalist view of the arts, in this case music, envisioned by Du Bois and utilized its reach and appeal for material and nihilistic ends. This exacerbates the problem when songs with violent and dehumanizing messages help shape popular culture.

The Influence of Music on Mood and Helping Behavior. Evidence suggests that environmental factors influence people's mood. In a study designed by Gueguen and De Gail (2003) 8 confederates (4 young men and 4 young women) tested 800 passers-by. 
In half the cases a confederate smiled at the passerby who few seconds later had the opportunity to help another confederate who dropped his/her computer diskettes on the ground. The results found that the previous smile of a stranger enhanced later helping behavior. This was explained by the positive mood induced by the smile of the first interaction. These results were consistent with one study that tied touch, eye contact and voice expression to positive mood and helping behavior (Goldman \& Fordyce, 1983). Music with its variations in pitches, rhythms, melodies and lyrics affects mood, feelings and thoughts. To gauge the effect of music to helping behavior, North, Tarrant and Hargreaves (2004) conducted a study in which participants in two similar university gyms were exposed to either upbeat beat music designed to induce positive mood or annoying music designed to induced negative mood. The study showed that participants who were exposed to the upbeat music were more willing to engage in helping behavior immediately after workout. Another study by Anderson, Carnagey and Eubanks (2003) investigated the effect of lyrical content on thoughts and feeling. Researchers solicited suggestions of songs with the same length that fell into the same category: soft rock or hard rock. One of the song contained violent lyrics and the other did not or very minimally. The violent song was from the group Tool: “Jerk-Off” from the album Opiate in 1992. The non-violent song was from the same group Tool: "Four Degrees" from their album Undertow in 1993. Twenty nine females and 30 male participants first listened to a contemporary song and then answered a few questions about the song. Then they were assigned one of the Rock songs and completed the state hostility scale (SHS; Anderson et al, 1995) soon after. The SHS contains 35 sentences describing current feelings (either hostile or friendly). For instance two hostile items read, "I feel like yelling at somebody" 
and "I feel furious". Using a 5-point Likert type scale (1= strongly disagree, 3 neither agree nor disagree, 5 strongly agree) respondents rated each sentence. The friendly items were reverse scored. The results revealed that the violent content of Rock songs can increase feelings of hostility when compared with similar but non-violent rock music. And this without any provocation. Additional studies by Ganser and Huda (2003) have also shown that songs had significant impact on mood. They influence moods both positively and negatively. Greitmeyer (2009) analyzed the relationship between music and actual behavior. Participants were told they were doing marketing research on music preference for which they would be paid. When they were given the money at the end of the fake study, the researcher mentioned a donation box for a non-profit organization to which they could donate their earnings, but there was no obligation. Participants who were exposed to pro-social content were more likely to donate money than participants who heard a neutral song.

It is important to note that the literature also has a body of work that finds no effects of lyrical content on aggression-related variables (e.g Ballard \& Coates, 1995; St. Lawrence \& Joyner, 1991; Wanamaker \& Renikoff, 1989). For example , Ballard and Coates found that lyric content had no impact on mood measures including anger when participants listened to one of six songs varying in genre (rap vs. heavy metal) and lyrical content (homicidal, suicidal, neutral). It is worth noting in some of the studies showing no effect, the genre of the songs at times (heavy metal) made it hard to understand the lyrics.

In summary while there is considerable evidence that pro-social lyrics influence mood and helping behavior, the literature has produced mixed results. This could be 
because of methodological considerations involving confounds with arousal or lyrics that are indecipherable.

Music Performance Evoking Empathic Responses. Music is a communication channel that helps express thoughts and feelings in ways words cannot. Music performance is often viewed as part of a system of communication whereby a composer encodes ideas in musical notations, a performer recodes such message to acoustic signal and listeners recode the later into ideas (Kendall \& Carterette, 1990). Palmer (1997) suggests that each performer prior to a performance has the intentions to convey their conceptual interpretation of the musical composition. By means of fluctuations in timing and sound intensity within performances, musicians intensify emotional communication (Palmer, 1997).

A study that investigated the dynamics of emotional and neural responding to a music performance, focusing on the role of stimulus parameter dynamics and listener experience, has revealed that expressive music performance evokes emotion and reward related neural activations in a network consistent with the human mirror neuron system. The study has shown that music's affective impact on the brains of listeners is altered by musical training as well (Chapin \& Jantzen \& Kelso, 2010).

In the study Chapin, Jantzen and Kelso (2010) observed by means of fMRI emotional responses and neural activity as they evolved together with stimulus parameters over several minutes. Participants listened to a skilled music performance that included the natural fluctuations in timing and sound intensity that musicians use to evoke emotional responses. A mechanical performance of the same piece served as a control. Before and after fMRI scanning, participants reported real-time emotional 
responses on a 2-dimensional rating scale (arousal and valence) as they listened to each performance. During fMRI scanning, participants listened without reporting emotional responses. Limbic and para-limbic brain areas responded to the expressive dynamics of human music performance and both emotion and reward related activations during music listening were dependent upon musical training.

These findings are consistent with the idea that music performance evokes an emotional response through a form of empathy. The more musically experienced listeners (either performance or listening) were more sensitive to the temporal dynamics of expressive rhythmic performance. Additionally, Levitin (2007) states that many composers use chord progression, cadence and modes within scales to set and control moods in a musical piece.

Having established that music has the potential to affect mood and influence helping behavior through both lyrical content and musical composition and performance, I now will review what the literature suggests about its capacity to evoke empathy.

Can Empathy be Evoked through Songs? To answer this question, I must first answer the following three questions: Can empathy be evoked through our senses? If yes, how is empathy evoked? And finally, can such process be adapted to songwriting and song performance?

A review of the literature suggests that empathy can be triggered through our senses. The discovery of mirror neurons located in the pre-motor area of the brain sheds light on the neurobiological processes of empathy (Manney, 2008). These neurons are responsible for the internal representation of what one observes. They are also the same 
neurons that get triggered when one performs the same observed action (Carr, Iacoboni, Dubeau \& Mazziotta, 2002). These conclusions were reached after a study was conducted on 11 healthy right-handed individuals whose brain scans were monitored as they were presented magnet compatible goggles each containing randomly ordered depictions of six emotions (happy, sad, angry, surprise, disgust, and afraid) and were asked to observe, to imitate and to internally generate the target emotion on the computer screen. The study revealed that there was a substantially similar network of activated areas for imitation and observation of emotions (Carr et al., 2002). These findings suggest that the neurological circuitries used to process and generate emotional responses to stimuli are essentially the same as the ones used when one is imitating and/or performing the same stimuli. This not only means that empathy can be evoked by cognitive imitation, but also implicitly by the stimulation of one's senses.

How to Systemize the Stimulation of Empathy? The literature suggests that the modeling of desired empathic response, and the provision of narrative that gives additional context about a person being observed, effectively evoke empathy in a target audience. A study conducted by Schrandt, Townsend and Poulson (2009) with the purpose of investigating ways to automate empathic response with autistic children have found that modeling the process of empathic response is highly effective. In the study instructors presented to four autistic children vignettes with dolls and puppets demonstrating various types of affect and used prompt delay, modeling, manual prompts, behavioral rehearsals and reinforcement to teach participants to perform empathy responses. They concluded that "modeling" both the identification of emotions and 
appropriate empathic responses is helpful in teaching empathy to autistic children.

In addition to modeling empathic responses, the provision of narrative (context and information about a person or a case) has proved to be effective in evoking empathy. One such study conducted by Goodman-Snitkoff (2006), in which ample information about a patient was gathered, helped develop empathy with pharmacy students. In this study the response of pharmacy students to a traditional case study and an enriched, narrative-like, case study were compared. Students were presented either an enriched or traditional case study. After which students answers questions about the patient. The analysis of the responses provided evidence that pharmacy students in the group presented with the enriched case study exhibited a significantly stronger empathetic response to the patient that those presented with the traditional case study.

Another study that helps support the hypothesis that storytelling is an effective catalyst for empathic response is the one designed by Chestek (2010). In a study testing the hypothesis that a story based narrative woven with arguments (story reasoning) would be more persuasive than a strictly fact based argument narrative to appellate judges, Chestek wrote information-based narratives (logos briefs) and two story briefs. Each pair of briefs addressed opposite sides of a hypothetical case in a fictional jurisdiction. Because one of his hypotheses was that stories would have more impact in a case where the legal support for one side is weak, one of the fictional case he created involved a hard case. Chestek then recruited 95 participants in the judicial field who read the briefs about the cases and completed an online survey tool that asked them various questions about the degree of persuasion each brief had with regard to the case. Based on the results 
Chestek concluded that his hypothesis was correct in all cases: in both easier and harder cases, story base narrative was more persuasive. He posits that the reason is because stories are a method of structuring information in an engaging form that evokes more emotional response.

In summary, these three studies highlight two key processes relevant to this research. They emphasize systematization of sense stimulation via "modeling" and “storytelling". Manney (2008) also suggested that "storytelling through the imaginative act of the reader transacting words on a page into thoughts and feelings, hence enabling them to see the world through the character's eyes and to feel their feelings was the key to teaching empathy “(p. 3). Building on the mirror neurons finding, Manney (2008) along with many other scholars believes that when the stimuli is non-visual, the psychological impact on the subject's empathy is greater because the non-visual stimulation relies on the subject's mind and personal experiences to build its recognition. Thus the subject becomes co-creator of the story (p. 4). Additionally to its ability to stimulate mirror neurons and to enable us to relate to theme and characters different to us, storytelling also allows our minds to think outside the box of our own experiences, to develop creative ways to problem solve and to change our perspective (Butcher, 2006). These qualities make storytelling a potent educational strategy.

Always in an effort to best inform the pedagogical model that will help evoke empathy by means of songs and stories; I next would like to take a closer look at stories their impact on learning and knowledge formation. 


\section{Stories and Knowledge}

Schank (1995) states that knowledge is comprised of the stories we remember. The stories we remember are the ones we know, having learned them from our experiences. Our knowledge base is composed of our own stories that we tell as a way to solidify their meanings. Each time we tell stories, we teach ourselves the point of the stories which helps us deepen our understanding of them. And they wind up defining us. Schank \& Berman (1995) derive that people learn by telling stories rather than listening to them. To do so, they create stories to tell from their own experiences. Consequently they argue that the best way to teach is to create experiences likely to help create desired narratives in a targeted audience. Schank and Burman (1995) in their Story Centered Curriculum model (SCC) argue that schools should provide a framework that mirrors real life. This allows students to live an experience, which leads them to create stories (knowledge) needed to navigate real life scenarios. Shanck and Berman suggests that for an effective SCC one must first keep in mind the targeted set of skills the students will learn; who uses these skills in real life, when they are used and why. The answer to the question "who uses the skills" defines the active role attendees will play in the story. Figuring out when they use these skills elicits the kinds of stories or situations the students will be placed in. Finally by answering the why provides the goal used to cause students to want to practice the target skill set.

Gerrig (1993) in an earlier work which focuses on cognitive processes in narrative comprehension established that readers of a narrative piece experience two powerful phenomena. First, they are transported into an alternate space and time in such a compelling manner that it feels real. Second, they become performers in the narrative and 
like actors in a play they begin drawing inferences and feeling emotions. Based on this work Mott, Callaway, Zettlemoyer, Lee and Lester (1999) advanced the idea of narrative centered learning environments where learners can engage in co-construction, exploration and reflection. The authors suggest that in a narrative centered curriculum, learners can actively participate in the evolution of characters and the narrative. They believe that such framework allows for active exploration of characters' intentions and actions. Finally, they see it as way for learner to engage in "post-hoc analysis activities" where they reflect on the narrative experiences and the underlying subject matter. Mott, Callaway, Zettlemoyer, Lee and Lester (1999) argue that though intuitively language arts might appear to be the most suitable subject matter where narratives could be used as pedagogy, other subject matters can benefit significantly as well. In mathematics, narrative could shift the focus from mechanical algorithmic problem solving, e.g., arithmetic, to a more analytical approach to real-world problems that emphasizes analyses. In the sciences, an inquiry-based curriculum featuring dynamic narratives of the highly nonlinear process of scientific discovery could foster an in-depth understanding of how real-world science plays out. In social studies, biographies could shift the focus from rote memorization of facts and dates to an analysis of compelling historical figures, their motivations, and the geographical contexts in which they lived. (p. 2)

Mott et al (1999)'s fundamental hypothesis in their work is that by enabling learners to be co-constructors of narratives, narrative centered learning environments can promote deep-connection-building and meaning making that defines constructivist learning (Mott et al.., 1999). One additional nuance worth highlighting is the fact that 
narratives are a bit more than storytelling. They are about people engaging with the story and acting in a setting. The outcomes of this creative process must be relevant to the cocreators (beliefs, desires, theories and values (Bruner, 1991)).

The notions of constructive learning, co-creation, investigation and reflection are big lessons from this section. By creating an experience in which learners are transported into a narrative they can impact through action of their own, we can witness the type of engaged empathy defined in earlier sections of the literature review. As established by the various authors, in order to create an effective narrative learning environment, the story must be compelling, the audience must be able to partake in the unfolding of the story, investigate it and reflect on the overall experience. These are elements of the Song and Story Centered Pedagogy which will be introduced shortly after considering cultural dimensions of empathy and its arousal.

\section{Cultural Considerations}

Prior to presenting the Song and Story Centered Pedagogy, I deemed it important to assess cultural considerations regarding empathy. Is empathy universal? Are the outcomes of empathy cross-cultural? Iaccoboni (2009) in his discussion of intersubjectivity (the sharing of meaning between people), argues that the old argument that humans only had access to their own minds and therefore could not possibly understand the minds of others and share in their mental states, is an underestimation of our ability to access other minds by means of neural mechanisms of mirroring and simulation. He states:

The most basic property of mirror neurons -that is, firing for both the action of grasping a cup and the equivalent grasping action I only observe - suggests that they are 
helpful for recognizing the actions of other people(...). Given that our own actions are almost invariably associated with specific intentions, the activation in our brain of the same neurons I use to perform my own actions when I see other people performing these actions may also allow me to understand the intentions of the other people (p30).

One question remains: is the formation and interpretation of action dependent upon one's social conditioning? Siegel (2004) states that our brains even in infants are able to make generalizations or mental models from repeated experiences. Models generated serve as a kind of view, perspective or state of mind that directly influence the way we perceive and the way we respond in the future. Culture can be defined as the sum of ideals, values and assumptions about life that are widely shared and that guide specific behaviors. Culture influences our experiences and our interpretations of the world. As such, it can prevent us from experiencing and understanding other people's emotional states.

Although during the 1960s, research in the communication of emotions demonstrated strongly that the recognition of emotion was likely universal (Elfenbein \& Ambady, 2003), Matsumoto and Asar (1992) argued that it is because researchers were focused on establishing universality and consequently did not pay attention to cultural differences and crosscultural similarities. Elfenbein and Ambady (2003) believe that in the same manner emotional message is retained across cultural barriers, some of the message gets lost along the way as well. They illustrate this point with the sentiment many people express when living abroad or working in an international institution: that their basic communication signals tend to be misinterpreted. They therefore suggest that the 
expression of emotions is largely universal but there are subtle differences across cultures that can create a challenge for effective communication. Hence in order to enhance crosscultural emotional recognition, it is important to use tools that communicate emotions in a universal manner. Music and storytelling are common to all cultural traditions for expressing emotions. The journey of the hero who faces challenges and eventually overcomes adversity resonates across cultures. That is a formula of success that most Hollywood movie directors have mastered.

Having established that music is an effective tool for communicating emotions and stimulating empathy in a listener; having also established that storytelling is a great vehicle for providing proxy-experiences and giving perspective which is known to stimulate empathic concern, I now introduce the Story and Song Centered Pedagogy workshop which was informed by 10 years of action research.

\section{The Story and Song-Centered Pedagogy (SSCP)}

In this section I present the evolutionary process that led to the design of the Story and Song Centered Pedagogy in its current format. As anecdotal evidence of the effectiveness of the SSCP to evoking empathy, I interweave anecdotal stories of successful SSCP interventions that resulted in empathetic responses and transformational experiences. I then end with an outline of the key features of the pedagogy and show how they overlap with some key findings that emerged from the literature thus far.

From PowerPoint to performances. In its infancy, the presentation was designed to promote intercultural exchange between Oregonians and the rest of the world. As a recipient of the Inter-Cultural Services Program scholarship (ICSP), I went into classrooms across Oregon to share about my experience growing up in West Africa. 
Very quickly, facts and trends about the African continent projected on a screen seemed less relevant for youth than accounts of personal stories. On multiple occasions students would report that my stories (personal or those of friends growing up) helped them debunk the myths about Africa and helped them connect real people to the continent.

Songs came into the picture as I allowed students to probe into my personal stories. On repeated occasions as the topic of music and my passion for it were discussed, students wanted to hear samples of my work. The gasps of disappointment were so loud and heartbreaking the times I did not have a recording available. I then began bringing CDs to my presentations consistently. This also very soon began to feel like a lifeless version of an experience that could be much more engaging and dynamic. The story and song centered pedagogy was born in its closest iteration of the current format the first time I walked into a classroom with a guitar. Murmurs, curiosity, and excitement amid many other reactions were palpable. The presence of the guitar commanded attention and helped keep students focused and interested the length of the presentation.

Out of the need to best manage the classroom during my presentations, I began being more methodical. Questions such as "When do I sing the first song?", "How many songs do I sing?", "How do I connect a song to a particular topic and make it relevant?", "Which new songs should I write to help approach a topic?", "Which open-ended questions should I ask after a song?", "How do I differentiate between Middle schoolers and High schoolers?" helped inform the format and content of the SSCP.

A student's story informing the SSCP. Once, at one of the presentations in a high school classroom, I shared about my experience living in Portland Oregon as an immigrant and the challenges that ensued (language barriers, climate, diet). I then shared 
about the transformational impact some individuals have had on my experience when they extended unconditional acceptance. I shared 2 songs titled "Home" and "Faceless Love" (Appendix A). One student commented that the classroom was her only home because her household was unsafe. This led to one of the most transformational class discussions I had witnessed to date. We began talking about the impact of bullying on people whose only safe havens are the schools. This student's contribution was a critical milestone for the SSCP. From then on I was intentional about including stories of students from previous workshops and was on the lookout for authentic stories that would inspire and move my audiences.

A Collective Response to the SSCP. One such authentic story was that of a 10year old Haitian earthquake survivor who inspired the song "Nou Tout Haitien" (Appendix A). The song was written as an empathetic response after my encounter with this girl in Port au Prince a year after the infamous earthquake. I wrote the song as a way to give a voice to her story and to bring awareness about the situation in Haiti. The very first time I included the story in the workshop, one student during the class discussion asked about specific ways she and her classmates could get involved and make a difference. Unfortunately I had no concrete outlets to offer and pointed her to Google. I walked out of the workshop disappointed and frustrated at the fact that I missed an opportunity to channel an empathetic response into concrete helping behavior. This also, was a pivotal moment in the evolution of the SSCP. Upon reflection I realized that since the workshops was causing empathetic responses, it was critical that I provided ways for people to positively affect the outcomes of the stories I was telling: provide a way for them to co-write the narrative by participating in the story through social action. I began 
collecting a list of organizations or causes I would recommend as channels for social action. The second time I included the "Nou Tout Haitien" song in a workshop, it led to a fundraiser put together by a group of students. They purchased books that were donated to an elementary school in Haiti through a not for profit organization.

A Teacher's Story of Transformation. Over the course of 10 years of reflective practice, I have heard and witnessed a number of inspirational comments and stories that kept me passionate about this work. As a practitioner driven by a desire to cause social transformation by means of songs, there was nothing more powerful than hearing from teenagers on multiple occasions words one could only hope to hear once or twice during a career: "You have changed my life". While my greatest source of affirmation continues to come from the students I work with, there was one particular teacher whose experience of the SSCP confirmed beyond measure the importance and effectiveness of this pedagogical approach.

I was contacted by a high school foreign language teacher once, to come as a guest performer and sing songs in French for $1^{\text {st }}, 2^{\text {nd }}$ and $3^{\text {rd }}$ year students. Upon explaining the SSCP and the topics I usually address, I did not sense a particular interest beyond the foreign language connection at first. And though $90 \%$ of the workshop ended up being presented in English because of student's average to low proficiency level in French, I was asked to come back the following year. More importantly, after witnessing the positive impact on the students, the teacher would specifically request certain songs and topics for some class periods because of some individuals in these classes needing intervention. This partnership with this instructor is a validating testimony to the transformational impact of the SSCP on students. This experience also led to the creation 
of a differentiated SSCP curriculum that focuses on particular topics such as bullying, social action and self and peer awareness to name a few. This so far, is proving to lead audiences into more in depth conversations about each topic.

Key elements of the SSCP. In the previous sections, I outlined the key milestones in designing the Story and Song Centered Pedagogy. Through action research I kept infusing new techniques and practices into the design and execution of the SSCP to augment its effectiveness. Now I would like to summarize the key elements that comprise the SSCP to date and highlight some overlaps with the literature review.

First, the SSCP requires authentic stories and songs. Since the end goal is to trigger empathic responses from an audience, my experience has revealed that attendees make better personal connections when the story, the character in it and the songs used are original. As a result, people develop empathy towards the character of the story and want to help him or her. Also, by association, the audience wants to help anyone whose story resembles that of the character in the story. Very similarly to action heroes, the audience is also most likely to want to emulate behaviors and responses exhibited by the character of the story. This is a great way to model empathetic responses or positive conflict resolution techniques such as perspective taking as informed by the literature. Second, the SSCP requires an outlet where audiences can channel their empathetic responses. In my experience over the years, upon feeling empathetic concern, most youth do not know how to effectively channel the emotion into action steps. If the story is one the audience can help positively transform, providing venues for taking action empowers the audience and removes unnecessary obstacles. This characteristic of the SSCP resembles the concept of narrative learning environments put forth by Mott et al.(1999) 
and the concept of Story centered curriculum championed by Schank and Burman (1995). In the cases where the audience has no way of impacting the specific story, it helps to provide options where similar stories or causes can be impacted.

Last, to help facilitate discussions and to engage audiences cognitively, the SSCP requires reflective activities driven by thought provoking questions. Such questions can target dimensions of Self-awareness, Peer-awareness, modeled or instructed perspective taking behaviors, opportunity for action taking and self-reflection. Appendix B provides a list of songs and discussion questions targeting these dimensions.

\section{Measuring Empathy Quantitatively: the Interpersonal Reactivity Index}

The Interpersonal Reactivity Index (IRI) is widely recognized and used as a measurement tool for empathy across several disciplines. It has consistently demonstrated validity and reliability for various student populations (Davis, 1983). Cliffordson, (2001) has argued that that the Empathic Concern subscale of the IRI measures sympathy and rather than empathy. Davis $(1980,1983)$ index is based on the premise that Empathy only has two dimensions: affective and cognitive.

The IRI provides scores on four different components of empathy:

1. Personal distress: the tendency to experience distress and/or discomfort when witnessing another person's distress (e.g., "Being in a tense emotional situation scares me.”).

2. Empathic concern: the tendency to feel sympathy and/or concern for others in negative situations (e.g., "I often have tender, concerned feelings for people less fortunate than me.").

3. Fantasy: The fantasy scale measures the tendency to imaginatively transpose oneself 
into fictional situations ("When I am reading an interesting story or novel, I imagine how I would feel if the events in the story were happening to me").

4. Perspective-taking: the ability to take the psychological point of view of another person (e.g., "I sometimes find it difficult to see things from the 'other guy's' perspective.”).

Consequently, this is an appropriate tool to help assess the effect of the SSCP intervention. The IRI includes two affective sub-constructs of empathy; one focused on the self (Personal Distress) and the other focused on the-other (Empathic Concern). It also includes two cognitive sub-constructs of empathy: Perspective Taking which is other-centered and Fantasy which could be considered self-centered but in reality allows the self to travel into fictional settings. As referred to earlier, based on the work by Hoffman's $(1984,1987)$ there are some key relationships between these sub-constructs that are relevant for the study. See Figure 1: Hoffman's $(1984,1987)$ Empathy's relationships (p. 31).

\section{Summary}

In summary the literature review strongly suggests the existence of a neurobiological mechanism for empathy. This process can be evoked through conscious cognitive perspective taking (de Wied et al, 2007). It can also be activated by the effective use of storytelling. The cognitive nature of effective empathizing makes it possible to be evoked through storytelling because storytelling provides a framework for the storyteller to structure his characters and their actions in a way that models the cognitive empathetic processes that he wants his audience to imitate. 
The literature also shows that music composition by means of chord progressions, choice of scales and cadence sets and alters the mood of a musical experience. Also, music performance through acoustic fluctuations in timing and sound intensity impacts the emotional response of an audience. In addition the review shows that lyrics matter. Pro-social lyrical content influences mood, thoughts and behavior. Stories and songs together provide a unique framework for modeling and communicating cognitive empathetic processes and emotional responses one desires the audience to emulate or learn. According to the literature both music and stories are cross-cultural techniques for conveying emotions. They engage both hemispheres of the brain and as such maximize learning and retention.

The literature has informed us that to be effective with this workshop, the songwriter must highlight emotions shared across the human experience (fear, hopes, love, hurt, joy) to steer the audience towards humanizing target objects. This is informed by a study that suggests that the identification of emotions and appropriate empathic responses is helpful in teaching empathy to autistic children (Goodman-Snitkoff, \&, Goodman-Snitkoff, 2009). The songwriter must do this both with the lyrical content of the song but also with the choice of chord progressions and melodies. The presenter must contextualize each song within a larger narrative that will resonate with the audience. According to Schank (1995) people need context to help them relate what they have heard to what they already know. Additionally, the presenter must provide an avenue for the audience to partake in the narrative if they are to better remember the experience. Finally the performer must convey the emotional message of the songs by means of 
rhythmic, sound and intensity fluctuations.

The SSCP, informed by years of action research, overlaps with the key findings

from the literature: the need of an authentic story the audience can resonate with and can be part of through empathetic social action. 


\section{Chapter III: Research methodology}

\section{Rationale for Quantitative Methodology}

This present study was primarily concerned with assessing whether the Story and Song Centered Pedagogy's qualitative positive impact on empathy informed by years of action research, would translate into a quantitatively measurable increase in empathy. More specifically it sought to verify whether the intervention augments an audience's ability for perspective taking and emotional concern which are 2 subscales of the well documented and validated Interpersonal Reactivity Index (IRI) (Davis, 1980).

Given these objectives, a quantitative experiment fitted well as a methodology. The existing IRI measurement tool identifies individual dispositions to empathy by measuring 4 subscales of Empathy. By attempting to intervene on the Perspective taking and Emotional Concern variables, the study assessed quantitatively whether the SSCP had an impact on these dispositional variables of Empathy. The tool was a 28 item questionnaire, self-reported and convenient for the purpose of the study. This was a cross-sectional study with pre-intervention and post-intervention data collection.

\section{Theory that Informs Intervention}

The literature review indicates that perspective taking can be taught via modeling. It also shows that an audience emulates empathic responses when appropriate empathic emotional responses are demonstrated through modeling. Based on these findings I wondered whether if by means of the SSCP we expose an audience to a series of songs written to highlight the commonality of the human experience (hurt, desire to be loved, dreams, hopes etc); and if these songs are arranged and structured in a way that tells a larger story of the human experience while demonstrating appropriate perspective taking 
and empathic emotional responses in certain situational contexts, then attendees will increase their ability to empathize. Such an increase should be reflected in an increase in the Emotional Concern and Perspective taking subscales of the IRI. Therefore, the null hypothesis is that there would be no difference pre and post intervention, and the alternate hypothesis is that there would be a difference in the positive direction (e.g. Youth would score higher in the post intervention testing).

\section{Participants}

Participants for this quasi-experiment were selected by convenient sampling. An email communication was sent to high school social studies teachers in the Portland metro area that included a description of the study, cover letters and parental consent forms. See Appendix C: Parents Cover Letter and Permission Forms. One professor from Roosevelt High School responded favorably after having volunteered his classroom 4 years ago for a pilot session. The experiment was conducted in two classroom periods and comprised in total 74 students. There was no control group because the IRI has been tested for internal validity and reliability (see Instruments and Measures).

\section{Instruments and Measures}

To measure the effect of the intervention, I used the IRI. This 28 item index was published after several rounds of questionnaire development. The first round comprised 50 questions, some of which were pulled from existing measures (e.g., Mehrabian \& Epstein emotional empathy scale; Stotland's Fantasy-Empathy scale, 1988), and the others were added. The new items targeted both the cognitive (capacity to adopt different perspectives) and emotional response aspects of empathy. The pilot questionnaire was administered to 201 males and 251 females who used a five point scale running from 0 
(does not describe me well) to 4 (describes me very well) to respond to the items. Analyses of the first questionnaire pointed to the existence of four key sub-constructs within the overarching empathy construct (fantasy, perspective taking, empathic concern, personal distress). These four sub-constructs were the strongest themes for both males and females although other less interpretable factors emerged as well. The second round of development focused on these four primary factors. According to Comrey (1978), Davis used a factor analysis results as an "heuristic tool" in refining the items to better measure the identified constructs (Comrey). In so doing, a 45-item version was created, by combining 1) items taken intact from the pilot questionnaire, 2) items adapted from the pilot questionnaire, and 3) new items written to align closely to one of the four subconstructs of empathy. The second questionnaire was administered on a similar scale to 221 males and 206 females. Several precautions were taken to ensure that the same factors from the first version would emerge from the responses to the newer questionnaire. Fantasy, perspective-taking, empathic concern and distress items emerged once more as the 4 sub-constructs of the overarching construct of empathy and were nearly identical in both sexes as in the first round. Finally, in order to produce the strongest and most reliable instrument Davis (1980) picked the items that indicated the sub-construct most heavily irrespectively of gender. Any item that was ambiguous as of which sub-construct it indicated was discarded. This led to a 28 -item instrument. This last questionnaire was administered to a third group of independent respondents who had not participated in the first rounds. The group comprised 579 males and 582 females. The results provided strong support for the utilization of the four empathy subscales. The internal reliability coefficients (Standardized Alpha) were computed for each subscale 
separately for each sex and it was confirmed that a reliable set of subscales had been developed. Additionally in order to assess the reliability over time, the instrument was tested on an independent sample that comprised 56 males and 53 females who completed the questionnaire twice with a 60 to 75 day gap between each trial. Both sexes exhibited satisfactory temporal stability with respect to the new empathy subscales (Davis, 1980).

\section{Subscale Inter-correlations and Implications}

The weak inter-correlations between the four empathy subscales showed that one's standing on a particular subscale is not a powerful predictor of scores on the other scales. Given the relative independence of the scales, a variety of "Empathy constellations" are possible from the IRI. Though this study primarily focused on the Perspective Taking and Emotional Concern subscales, participants in this study answered all 28 items on the questionnaire. This way the results showed whether the intervention affects the other subscales (Fantasy and Personal Distress) of Davis's instrument.

\section{Variables}

The independent variable for this research is the SSCP intervention: A story presented to an audience by means of songs and a narrative. This study focused on one single story: my personal journey as an immigrant from West Africa to the USA. It highlighted the challenges and the journey of adaptation I faced in a new environment. The dependent variables chosen for the study were the two subscales of the IRI index: Perspective Taking and Empathic Concern. The other subscales of Davis's index (Personal Distress, Fantasy) might turn out as secondary dependent variables as a result of the intervention.

The reason why I am primarily focused on the Perspective Taking and Emotional 
Concern subscales of the IRI is because the SSCP intervention was designed to intervene on 1) affect and 2) cognition. The desired impact on affect is for an audience to have an other-centered affective response. And the desired impact on cognition is for an audience to engage in perspective taking. I therefore assume that if the intervention is successful, the post survey scores of these sub-constructs of Empathy would increase.

\section{Procedure}

I conducted 2 SSCP workshops in December 2012 at Roosevelt High school. The school is part of the Portland Public School system and is overwhelmingly populated by students from low income families. The study was conducted in a social studies classroom in 2 consecutive class periods. Prior to the day of the intervention, the instructor distributed parental approval forms for parents' signatures. Before each workshop, I introduced myself as a Masters Candidate student from Portland State University conducting a study designed to assess the effect of songs and storytelling on young adolescents. Students were then handed the IRI questionnaire and given 10 minutes to fill it out. I explained to them there would be a follow-up survey given during their next class in order to capture the sorts of impact the workshop might have had on them. After the surveys were collected, students were also handed the lyrics of the songs to be performed during the workshop (see Appendix A: SSCP Songs' lyrics). By means of songs and narration I shared my story as an immigrant moving from West Africa to the USA, and the challenges I experienced in the transition. I performed an introductory rap song in French to build rapport with the audience. This approach was informed by past experiences that showed youth related and tuned in quicker when I displayed proficiency in a musical genre they value (see Appendix D: SSCP, History, design and 
procedure).The workshop included three songs "Nou Tout Haitians" -we are all Haitians, "Home", "Let's Face it", and "Faceless love" (for a thorough outline of story and songs sequence refer to Appendix B: SSCP presentation outline). Each song fit the narrative, and questions previously identified as triggers for cognitive processes were also asked (See Appendix B: SSCP presentation outline).

Two days later, students were handed a clean IRI questionnaire as a post-intervention test which they completed and returned to their classroom teacher. 


\section{Chapter IV: Data Analysis}

After collecting the surveys, every participant's pre-intervention survey was matched with his or her post-intervention survey. I then discarded surveys without a match and those not fully completed or those for which I did not receive parental approval. I wound up with 48 useable pre and post intervention survey pairs, 23 from class \#1 and 25 from class \#2. (See Table 1, p.56).

Table 1: List of Participants and Valid Surveys.

\begin{tabular}{|l|l|l|}
\hline & \#Participants & Useable surveys \\
\hline Class \#1 & 36 & 23 \\
\hline Class \#2 & 38 & 25 \\
\hline Total & 73 & 48 \\
\hline
\end{tabular}

\section{Statistical Methods}

Descriptive statistics of the pre-, post- scores and their differences were generated for each subscale. Mean, standard deviation, minimum, maximum and quartiles were reported. Histograms and scatterplots of the scores' differences were also generated (see Figure 3: Histograms and Scatterplots, p.62)

To assess the effect of the SSCP intervention on perspective taking, empathic concern, fantasy, and personal distress, I worked with a statistician. We conducted a paired-samples t-test between pre- and post- scores for each of these subscales. Such a test was chosen in order to account for the correlation between the scores for each subject (i.e. the same subject took both the pre- and post- test). We essentially looked at the 
differences in scores and tested whether the mean of the differences was equal to zero. We also calculated correlations between the differences and assessed their statistical significance. A p-value less than 0.05 was considered statistically significant. All the analyses were performed using Microsoft Excel 2007.

\section{Results}

Descriptive statistics and paired t-tests results are reported in Table 2. (p.59). The pre-post- empathic concern scores' differences range between -10 and -13 with a median of 0 . The perspective taking differences range between -9 and 15 with a median of -0.5 . The personal distress differences range between -6 and 11 with a median of 1 . The fantasy differences range between -9 and 19 , with a median of -1 . The histograms of those differences reveal that the values are evenly distributed around 0 . The shape of the distributions is bell-shaped, which is a necessary assumption for paired t-tests. There was no noticeable skewedness in the distributions.

Table 2: Descriptive Statistics of the 4 Subscales

\begin{tabular}{lccc|cc}
\hline & \multicolumn{5}{c}{ EMPATHIC CONCERN (N=48) } \\
\hline & PRE & POST & DIFFERENCE & $\begin{array}{c}\text { P- } \\
\text { VALUE }\end{array}$ & 95\% CI \\
\hline \begin{tabular}{lccc|c} 
Mean +/- Std \\
Deviation
\end{tabular} & $\begin{array}{c}18.2+/- \\
4.0\end{array}$ & $\begin{array}{c}18.4+/- \\
4.8\end{array}$ & $-0.21+/-3.9$ & & \\
Minimum & 11 & 8 & -10 & & \\
$1^{\text {st }}$ quartile & 15 & 15 & -2 & 0.7093 & $-1.33,0.91$ \\
Median & 18 & 18 & 0 & & \\
$3^{\text {rd }}$ quartile & 21 & 22 & 1.25 & & \\
Maximum & 28 & 27 & 13 & & \\
\hline
\end{tabular}




\begin{tabular}{|c|c|c|c|c|c|}
\hline & \multicolumn{5}{|c|}{ PERSPECTIVE TAKING (N=48) } \\
\hline & PRE & POST & DIFFERENCE & $\begin{array}{c}\text { P- } \\
\text { VALUE }\end{array}$ & $95 \% \mathrm{CI}$ \\
\hline $\begin{array}{l}\text { Mean +/- Std } \\
\text { Deviation }\end{array}$ & $15.5+/-5.1$ & $\begin{array}{c}15.2+/- \\
4.1\end{array}$ & $0.27+/-3.9$ & & \\
\hline Minimum & 4 & 6 & -9 & & \\
\hline $1^{\text {st }}$ quartile & 13 & 13 & -2 & 0.6328 & $\begin{array}{r}-0.86 \\
1.40\end{array}$ \\
\hline Median & 15.5 & 15 & -0.5 & & \\
\hline $3^{\text {rd }}$ quartile & 18 & 17 & 2.25 & & \\
\hline \multirow[t]{3}{*}{ Maximum } & 28 & 27 & 15 & & \\
\hline & \multicolumn{5}{|c|}{ PERSONAL DISTRESS (N=48) } \\
\hline & PRE & POST & DIFFERENCE & $\begin{array}{c}\text { P- } \\
\text { VALUE }\end{array}$ & $95 \% \mathrm{CI}$ \\
\hline $\begin{array}{l}\text { Mean +/- Std } \\
\text { Deviation }\end{array}$ & $12.7+/-4.5$ & $\begin{array}{r}11.6 \\
+/-4.3\end{array}$ & $1.10+/-3.5$ & & \\
\hline Minimum & 4 & 1 & -6 & & \\
\hline $1^{\text {st }}$ quartile & 9 & 10 & -1 & 0.0331 & $\begin{array}{c}0.09 \\
2.12\end{array}$ \\
\hline Median & 13 & 11 & 1 & & \\
\hline $3^{\text {rd }}$ quartile & 16 & 14 & 3 & & \\
\hline \multirow[t]{3}{*}{ Maximum } & 21 & 22 & 11 & & \\
\hline & \multicolumn{5}{|c|}{ FANTASY $(\mathrm{N}=48)$} \\
\hline & PRE & POST & DIFFERENCE & $\begin{array}{c}\text { P- } \\
\text { VALUE }\end{array}$ & $95 \% \mathrm{CI}$ \\
\hline $\begin{array}{l}\text { Mean +/- Std } \\
\text { Deviation }\end{array}$ & $15.6+/-4.8$ & $\begin{array}{r}15.6 \\
+/-5.6\end{array}$ & $-0.20+/-4.7$ & & \\
\hline Minimum & 6 & 2 & -9 & 0.9756 & $\begin{array}{r}-1.38 \\
1.34\end{array}$ \\
\hline $1^{\text {st }}$ quartile & 12 & 12 & -3 & & \\
\hline Median & 15 & 15 & -1 & & \\
\hline
\end{tabular}




\begin{tabular}{lccc}
\hline $3^{\text {rd }}$ quartile & 20.25 & 19 & 2.25 \\
Maximum & 24 & 26 & 19
\end{tabular}

The paired t-tests results suggest that the SSCP intervention had no significant effect on empathic concern, perspective taking and fantasy scores: there was no statistically significant difference between pre- and post-empathic concern scores (mean difference $=-0.21, p$-value $=0.7092)$; there was no statistically significant difference between pre- and post-perspective taking scores (mean difference $=0.37, \mathrm{p}$-value $=0.6328$ ); there was no statistically significant difference between pre- and post- fantasy scores (mean difference $=0.20, \mathrm{p}$-value $=0.9756$ )

However, the difference between pre- and post-personal distress scores was statistically significant. The mean difference was 1.1 and the p-value 0.0330 (less than 0.05). The $95 \%$ confidence interval for the mean difference was $0.09-2.12$. These results suggest a statistically significant decrease in personal distress scores after the SSCP intervention.

We observed the highest correlation between fantasy scores differences and empathic concern scores' differences: 0.56 with a statistically significant p-value (less than 0.0001). This positive correlation means that as the Empathic Concern scores' differences increased, the Fantasy scores' differences also increased.

The correlation between Perspective Taking and Empathic Concern, although weak $(0.32)$, was statistically significant ( $p$-value $=0.0267$ ). Likewise, the correlation between Perspective Taking and Fantasy scores' differences was statistically significant 
but weak: 0.36 , p-value $=0.0112$. The other correlations were very low and not statistically significant (see Table 3, p. 60).

Table 3: Correlation between Differences

\begin{tabular}{l|cccc}
$\begin{array}{l}\text { Correlation } \\
\text { (P-value) }\end{array}$ & $\begin{array}{c}\text { Empathic } \\
\text { Concern }\end{array}$ & $\begin{array}{c}\text { Perspective } \\
\text { Taking } \\
\text { Differences }\end{array}$ & $\begin{array}{c}\text { Fantasy } \\
\text { Differences }\end{array}$ & $\begin{array}{c}\text { Personal } \\
\text { Distress } \\
\text { Differences }\end{array}$ \\
\hline Empathic Concern & - & & & \\
Perspective Taking & $\begin{array}{c}0.32^{*} \\
(0.0267)\end{array}$ & - & - & \\
Fantasy & $\begin{array}{c}0.56^{*} \\
(<.0001)\end{array}$ & $\begin{array}{c}0.36^{*} \\
(0.0112)\end{array}$ & & \\
Personal Distress & 0.12 & 0.11 & 0.20 & - \\
& $(0.3944)$ & $(0.4347)$ & $(0.1745)$ & \\
\hline
\end{tabular}

*Statistical Significant Correlations

\section{Discussion}

The results of the study indicate that by using the IRI, there was no statistically significant increase in Emotional Concern or Perspective taking after the SSCP intervention. This is in direct tension with the overwhelmingly compelling anecdotal evidence gathered through action research that shows that the SSCP affects audience's ability to empathize. This raises a number of questions: Was the IRI the best tool to measure the effects of the SSCP on Empathy? Were the EC and PT scales the most appropriate constructs to capture the effect of the intervention on Empathy? Does the fact that the SSCP causes audience to empathize, necessarily translate into an increase in empathy? A number of limiting factors prevent us from an interpretative analysis of the results and other correlations. These factors are explored further below. Only a more rigorous quantitative study and/or a mixed methodology could help resolve this tension between the anecdotal evidence and the quantitative results. 


\section{Summary}

This preliminary study sought to assess whether the SSCP intervention would increase empathy by positively affecting the Perspective Taking and Emotional Concern subscales of the IRI. The results indicated that statistically, the impact of the SSCP on those two scales was insignificant. This is inconsistent with the anecdotal evidence gathered from action research that shows that the SSCP affects students' ability to empathize. This raises a number of questions and leaves room for future research to help identify the most effective method to quantitatively measure the impact of the SSCP. 


\section{Chapter V: Limitations and Recommendations for Future Research}

\section{Limitations}

There were a few challenges that might have affected the accuracy of the data. Because of an extremely busy week leading up to the visit, the instructor of the two classes of participants was unable to distribute the pre-test IRI surveys before the workshops. Consequently the participants had to complete their surveys hastily the morning of the intervention. Given the haste, many students did not appear to give as much attention or thoughtfulness to the questions as would have been desirable and optimal for the study. They were also given the post-intervention surveys too soon after. Should they have been given more time to process the content of the workshop, maybe the Perspective Taking scores would have been much higher. Based on prior pilot studies, I was told by teachers that though students appeared quiet during the workshops, they later shared that they needed more time to process all the content.

I was also informed after the session that students had been exposed to songs related to the civil rights' movement months prior. These songs were used to discuss the notion of human dignity. This could have been a contributing factor to the insignificant direct impact of the SSCP on the PT and EC scales. Lastly, the small sample size used in the study is likely a contributing factor for the statistically insignificant changes in the EC and PT scales.

\section{Recommendations}

Results of this study raise some questions and some changes in protocol. For future research I would recommend a) a more rigorous and a larger sample size study to better capture the changes in the various scales, b) a mixed methodology study to 
compare qualitative and quantitative results, c) a more targeted SSCP intervention by using one single song associated with a story. This will also give room for more engaging activities to help deepen the reflection which could cause a greater increase in Perspective Taking.

\section{Conclusion}

This preliminary study sets a foundational framework for conflict resolvers who are interested in using music to enhance empathy within the context of conflict prevention or conflict resolution. Though the results were not consistent with the anecdotal evidence collected through action research, this study introduces and makes a scholarly case for the Story and Song Centered Pedagogy. Informed by action research and a review of the literature, the SSCP has the potential to help invigorate and transform empathy education for youth. 


\section{References}

Abi-Ezzi, K., Boyce-Tillman, J., Cohen, C., Galtung, J., Jordanger, V., Kent, G. (2008). Music and conflict transformation: Harmonies and dissonances in geopolitics. (O. Urbain, Ed.). New York: I.B.Tauris \& Co Ltd. American Music Therapy Association, 2011. Music Therapy in response to crisis and trauma. Retrieved from http://www.musictherapy.org/assets/1/7/MT_Crisis_2006. pdf

Anderson, C. A., Carnagey, N. L. \& Eubanks, J. (2003). Exposure to violent media: The effects of songs with violent lyrics on aggressive thoughts and feelings. Journal of Personality and Social Psychology, 84(5), 960-971.

Asia Society (2013). Educating for Global competence: Educating our youth to engage the world. Retrieved from http://asiasociety.org/files/book-globalcompetence.pdf.

Augsburger, D. W. (1992). Conflict mediation across cultures: Pathways and patterns. Westminster/John Knox press.

Avruch, Kevin (1998). Culture and Conflict Resolution. United States Institute of Peace.

Ballard, M. E., \& Coates, S. (1995). The immediate effects of homicidal, suicidal, and nonviolent heavy metal and rap songs on the moods of college students. Youth \& Society, 27(2), 148

Batson, CD., \& Ahmad, N. (2001). Empathy-induced altruism in a Prisoner's Dilemma II: What if the target of empathy has defected? European Journal of Social Psychology, 31(25)-36.

Batson, CD., \& Moran, T. (1999). Empathy-induced altruism in a Prisoner's Dilemma. European Journal of Social Psychology, 29(7)909-924. 
Batson, CD. (1991). The altruism question: Toward a social-psychological answer. Hillsdale, NJ: Erlbaum Associates.

Bennet, M., \& Hibberd, M. (1986). Availability and the false consensus effect. Journal of Social Psychology, 126, 403-405.

Brotons, M., Koger, S. M., \& Pickett-Cooper, P. (1997). Music and dementias: A review of literature. Journal of Music Therapy, 34, 204-245.

Bruner, J. (1991). The narrative construction of reality. Critical Inquiry, 18, 1-21. Bullying Statistics, 2009. Cyberbullying Statistics. Retrieved from http://www.bullyingstatistics.org/content/cyber-bullying-statistics.html.

Butcher, S.E. (2006). Narrative as a Teaching strategy. The Journal of Correctional Education, 57(3).

Carr, L., Iacoboni, M., Dubeau, MC., \& Mazziotta, J.C. (2002). Neural mechanisms of empathy in humans: a relay from neural systems for imitation to limbic areas. PNAS $2003100(9)$ 5497-5502

Chapin, H., Jantzen, K., Kelso, J.A.,Steinberg, F. \& Large, E. Dynamic emotional and neural responses to music depend on performance expression and listener experience. PLoS One 5(12):e13812.

Chestek, K.D. (2010). Judging by the Numbers: An empirical Study of the Power Story. CIA. (2009). Retrieved from https://www.cia.gov/library/publications/the-worldfactbook/geos/xx.html)

Cliffordson, C. (2001). Parents' judgments and students' self-judgments of empathy. European Journal of Psychological Assessment, 17, 36-4 
De Wied, M., Branje, S.J.T, Meeus, W.H.J. (2007). Empathy and Conflict Resolution in Friendship Relations Among Adolescents. Aggressive Behavior, 33, 48-55.

Davis, MH. (1983). Measuring individual differences in empathy: evidence for a multidimensional approach. Journal of Personality and Social Psychology, 44, 113-126.

Decety, J., Ickes, W. (2009). The social neuroscience of empathy. Cambridge, Massachusetts: Massachusetts Institute of Technology Press.

Devoldre, I., Davis, H., Buysse, A. Empathy and social support provision in couples: Social support and the need to study the underlying processes. The Journal of Psychology 144(3), 259-284.

Eisengberg, N., Fabes, R.A, Schaller, M., Carlo, G., \& Miller, P.A. (1991). The relations of parental characteristics and practices to children's vicarious emotional responding. Arizona State University.

Elfenbein, H.A \& Ambady, N. (2003). Universals and cultural differences in recognizing emotions. Current Directions in Psychological Science, 12(5), 159.

Eyerman, R. (2002). Music in movement: Cultural politics and old and new social movements. Qualitative Sociology, 25(3).

Ganser, J., Huda, F. (2010). Music's effect on mood and helping behavior. UW-L Journal of Undergraduate Research xiii.

Gerdes, KE., Lietz, CA., Segal, EA. (2011). Measuring empathy in the 21st century: development of an empathy index rooted in social cognitive neuroscience and social justice. Social Work Research, 35(2), 83-93 
Gerrig, R. 1993. Experiencing narrative worlds: On the psychological activities of reading. New Haven, CT: Yale University Press.

Goldings, H. J. (1954). On the avowal and projection of happiness. Journal of Personality, 23, 30-47.

Greitnemeyer, T. (2009). Effects of songs with prosocial lyrics on prosocial thoughts, affect, and behavior. Journal of Experimental Social Psychology, 45(1), 186-190

Gueguen, N. \& De Gail, M. (2003). The effect of smiling on helping behavior: Smiling and Good Samaritan Behavior. Communications Reports, 16, 2

Goldman, M., \& Fordyce, J. (1983). Prosocial behavior as affected by eye contact, touch and voice expression. The Journal of Social Psychology, 121, 125-129.

Goodman-Snitkoff, G. \& Goodman-Snitkoff, L.S. (2006). Use of enriched case studies to enhance empathy in pharmacy students. Journal of Pharmacy Teaching, 13, 5-16.

Hoffman, M.L. (1984). Interaction of affect and cognition in empathy. In C. E. Izard, J. Kagan, \& R. B. Zajonc (Eds.), Emotions, cognition, and behavior, pp. 103-131. Cambridge: Cambridge University Press.

Hoffman, M.L. (1984). The contribution of empathy to justice and moral judgment. In N. Eisengberg \& J. Strayer (Eds.), Empathy and its development, pp. 47-80. Cambridge: Cambridge University Press.

Hulstijn, W., Kessels, R.P.C \& Tilborg, I.A.D.A (2011). Learning by observation and guidance in patients with Alzheimer's dementia. University of Antwerp. Collaborative Antwerp Psychiatric Research Institute (CAPRI), Belgium. 
Johnston, MK. (2010). Music and conflict resolution: Exploring the utilization of music in community development. Thesis, Portland State University.

Jones, E.E. \& Nisbett, R.E.(1972). The actor and the observer: divergent perceptions of the causes of behavior. In E. E. Jones, D. Kanouse, H. H. Kelley, R. E. Nisbett, S. Valins, \& B. Weiner (Eds.), Attribution: Perceiving the causes of behavior (pp. 79-94). Morristown, NJ: General Learning Press.

Katz, D., \& Allport, F. (1931). Student's attitudes. Syracuse, NY: Craftman Press.

Kendall, R.A., \& Carterette, E.C. (1990). The communication of musical expression. Music Perception 8(2), 129-163.

Knight, W. E. J. \& Rickard, N. S. (2001). Relaxing music prevents stress-induced increases in subjective anxiety, systolic blood pressure, and heart rate in healthy males and females. Journal of Music Therapy, XXXVIII(4), 254-272.

Kohler, W. (1929). Gestalt psychology. New York: Liveright.

Lederach, JP. (1996). Preparing for peace: Conflict transformation across cultures. Syracuse, NY: Syracuse Press.

Levitin, D.J. (2008). The world in six songs. Penguin group

LaMonica, EL. (1996). Empathy construct rating scale. Santa Clara: Xicom Inc., pp. 1-8. Manney, PJ. (2008). Empathy in the time of technology: How storytelling is the key to empathy. Journal of Evolution and Technology, 19(1), 51-61.

Marsden, R. (2009). Technology and the new 'me' generation: Computers and cell phones have become the narcissist's best friends. Onlinewsj.com http://online.wsj.com/article/SB1000142405274870415280457462796053258799 
$\underline{6 . h t m l}$

Mehrabian, A. (1988). Manual for the Balanced Emotional Empathy Scale. (Available from Albert Mehrabian, 1130 Alta Mesa Road, Monterey, CA 93940, USA).

Mott, B.W., Callaway, C.B., Zettlemoyer, L.S., Lee, S.Y. \& Lester, J.C. (1999). Towards narrative centered learning environments. AAAI Technical Report FS-99-01.

North, A. C., Tarrant, M., \& Hargreaves, D. J (2004). The effects of music on helping behavior: a field study. Environment and Behavior, 36, 266-275

O’Mahony, J. F. (1984). Knowing others through the self: Influence of self-perception on perception of others: A review. Current Psychological Research and Reviews, 3(4), 48-62.

Palmer, C. (1997). Music performance. Annual Review of Psychology, 48, 115-38.

Rifkin, J. (2009). The empathic civilization: The race to global consciousness in a world in crisis. Penguin Group.

Robertson, D. (2010). International trade: First principles forgotten.

Schank, RC., Abelson, RP. (1995). Knowledge and memory: The real story. Hillsdale, NJ. Lawrence Erlbaum Associates.1-85

Schrandt, J., Townsend, D., Poulson, C. (2009). Teaching empathy skills to children with autism. Journal of Applied Behavior Analysis, 42, 17-32

Senehi, J. (2000). Constructive storytelling in intercommunal conflicts: Building community, building peace. In Reconcilable differences: Turning points in ethno political conflict. (Eds.) Sean Byrne and Cynthia Itvin. West Hartford, CT: Kumarian Press. 
Siegel, D.J., Hartzell, M. (2004). Parenting from the inside out. Penguin Group.

Staub, E. (1987). Commentary on Part I. In N. Eisengberg \& J. Strayer (Eds.), Empathy and its development, pp. 103-115. Cambridge: Cambridge University Press.

Tillborg, IIse., Kessels, P.R.,Hulstijn, W. (2011). How should we teach everyday skills in dementia? A controlled study comparing implicit and explicit training methods. Clinical Rehabilitation 25(7) 638-648

Van Lange, P.A.M, Rumble, A.C., Parks, C.D. (2010). The benefits of e mpathy: When empathy sustains cooperation in social dilemmas. European Journal of Social Psychology, 40, 866.

Vecchi, GM. (2009). Conflict \& crisis communication: the behavioral influence stairway model suicide intervention. Annals of the American Psychotherapy Association, 12(2), 32-39.

West, C. (2004). Democracy matters: winning the fight against imperialism. Penguin Books.

Willard, N. (2003). Off-campus, harmful online student speech. Journal of School Violence, 1(2), 65-93. 
APPENDIX A

SSCP SONGS LYRICS

\section{Soldat sans contrat / Soldier without a contract}

\section{Chorus}

Dans mes textes c'est ce monde que je combats

In my lyrics it's this world system that I am fighting

Sans répit je médite et condamne

Relentlessly I meditate and condemn

Tous ces vices qu'ils nous servent tel un repas

All these vices they are serving us

Rien de plus je me bats tel un soldat

Nothing else, I am fighting like a soldier

Rien de plus je me bats sans un contrat

Nothing more, I fighting without a contrat

\section{Verse 1}

Premier texte déjà 15 ans j'atteste

It's been already 15 years since my first song

De tristes rimes écrites en une pleine nuit de stress

Sad rhymes written in the middle of a stressful night

Histoire de cœur une jeune demoiselle me blesse

A love story with a young girl who hurt my feelings

Aussitôt une plume vierge pour remplacer ses caresses

I took a pencil and a virgin sheet to replace her kisses 
Ainsi mon trajet commence dans les années 92

Hence, my journey started back in 92

Quand le groupe I AM régnait

When the rap group named I AM used to rule this game

De Shurik'n et AKH on s'imprégnait

My friends and I used to be inspired by Shurik'n \& AKH

On rêvaient d'hostile mais très vite on a résigné

We wanted to be signed by Hostil Records, but very soon we resigned

Car perdu l'envie d'être une star comme au Ciné

Because we lost the desire to become famous like movie stars

Préfère écrire pour les âmes enchaînées

We preferred to write for souls in chain

Donc nouvelles donnée écrire sans peur de gêner

Hence, we started writing without the fear of angering anyone

Décrire notre quotidien comme on l'a connu et mené

Talk about our reality as we know and live it

La carrière solo s'en suit un peu molo

My solo career followed shortly after

Je débarque aux USA pour le rap français oh no

I came to the USA, for french rap, this was not the right place

L'Amérique don't know les rimes de Oxmo

Americans did not know about Oxmo

C'est peine perdu de tenter de faire de la promo 
It was pointless to try to promote my craft

Changement de technique pas besoin d'Arsenic

I had to change my approach ; no need for arsenic

C'est pas une tragédie donc y a pas de panique

It was not a tragedy; so no need to panic

Y a pire que ça je sais demande a Mélanie

There are worse things in life ask Melanie

Je relativise polis mon art pour l'avenir.

I took the best out of the circumstance and sharpened my skills for the future

\section{Verse 2}

J'entends dire autour de moi que c'est un art de rue

I hear people say that rap is for people in the ghetto

Je dis que c'est l'art de qui du chemin on parcouru

But I say it's an artform for those who have suffered and come a long way

Car sans cela les textes de rap sont sans contenu

because without the life experience, the lyrics are without depth nor substance

Je suis pas le bienvenu mais je force ma venue

I know that I am not welcomed but I am forcing my arrival

Faire de la zik qui transforme et change des vies

Make music that impact and changes live is my goal

Prêcher le Christ et faire kiffer Ben Laden

Make mentions of Christ but yet have Ben Ladin dancing

Ca te semble impossible et bien c'est ma cible 
That might sound impossible but trust me that's my vision

C'est ce qui me fait vivre : «me nourrir de l'intangible»

That's what keeps me going: "I feed myself with the intangible"

Aucune envie de leurs victoires de la musique

I really care less about their grammys

Ce qui me motive le devenir de leurs fils

What drives me is the future of all the youth

Bien qu'ils me privent de leurs media je persiste

Though I have no access to their mainstream media I keep singing

Car mon seul guide le divin par qui j'existe

Because my only guide is the divine who sustains me

Des années passées à combattre leur refus

Year after year, combatting hurdles

A me laisser parler a présent le déluge

Attempts to keep my mouth shut, but now the lyrical flood

Ce titre un prélude, qu'ils cherchent un refuge

This is but a snapshot of what is coming down the pipe

Je ne mâche pas mes mots la vérité en dépit

I will not hold back my words, the Truth no matter what

Des conséquences de ma prose c'est ma devise

The consequences may be, that's my slogan

Prendre les rennes sans le besoin d'egotrip

No need to be conceited to take the lead 
Trop de choses a dire j' ai pas le temps a médire

Way too much things to share about for me to focus on petty talks

Sur quiconque ma mission seule me suffit.

The spelled out goals above are enough to focus on 


\section{Nou Tout Haitien / We are all Haitians}

\section{Chorus}

Ey yo Ey yo Ey yo Ey yo Eya

She is screaming aloud come help me she cries

Oun voule pati avec ou she said

(Take me with you)

Nou Tout Haitien

I'd say she was ten

\section{Verse 1}

She was wandering in the streets of Port au Prince

Watching over her two young brothers

Daddy's gone she is stepping up to help her mom

she looks at me and asked to be taken home

I was just a stranger, I could not save her

I did what I could I guess I tried to save her

Was it enough? Something is wrong with this picture

Only God's grace will carry her another day

\section{Bridge}

Her picture is on my mind, what more can I do?

I hope she is fine

Her picture is on my mind, what more can I do

Her story could've been mine 


\section{Home}

\section{Bridge:}

Where is home?

I want to know

will I return?

Would it be like years ago

Sometimes I feel so confused

But all I am truly missing is the love

\section{Verse 1}

I'll Make it my home

No matter what you say

I am packing my suitcase now, I'll go

No matter where God takes me

Cause I know now

It's the people who make it feel like home

Yes I know now

There is more than one place that I will call home

\section{Verse 2}

I'll make it my home

Cause I won't live in the past anymore

I am going to have new dreams new hopes

Cause I am alive and thankful to the Lord

Cause I know now 
It's the people who make it feel like home

Yes I know now

There is more than one place that I will call home

\section{Chorus:}

Now, every time I am asked where I am from

I'll tell everyone where there is love I am at home

Cause it's the people, it's the people who make it feel like home

\section{Bridge:}

Where is home?

I want to know

will I return?

Would it be like years ago

Sometimes I feel so confused

But all I am truly missing is the love

Cause it's the people, it's the people who make it feel like home

So I'll try to make someone else feel at home

I'll try 


\section{Let's face it}

Let's face it, I am the problem

I rather blame all these faces

Although it's so blatant

Cause I am always right

And Always justified

It's time for me to own it

I don't know how to take it

When facing other people who think differently

So I pick a fight or just choose to stay afar

\section{Chorus:}

One new song, one new story, one new life

I am changing my ways, I am changing my ways today

One new song, one new story

Change is on its way

Love is on its way today I swear

It's amazing, How much energy

I spend on judging others because I am unsecure

So I use my pride as a shield and hide behind

\section{Bridge}

Hypocrite, I don't want to be a Hypocrite

Screaming out world peace

But in my life spreading hatred. 
It is decided, today is a new day

Though I know we will disagree

I am not gonna violate your dignity

Cause I choose to love you

Oh Yes I choose to love you 


\section{Faceless love}

\section{Verse 1}

With all this pain and all this confusion

I was like a pilot in peril

I had no hope, no clear ambitions

I had no stake in tomorrow

Then you came to me with selfless intentions

Showed me the life in my sorrow

You held me up and said no words

You taught me how to be my own hero

\section{Chorus}

I found myself again

I found myself again

I found myself again

Because of your love

Selfless love

Because of your love

Faceless love

Because of your love

Courageous love

Because of your love

Tenacious love 


\section{Verse 2}

I am not the same, I surely came a long way

Though I am weak I am strong

I have no shame, no matter the loss or gain

I now can sing this song

Yes you came to me with selfless intentions

Showed me the life in my sorrow

You held me up and said no words

You taught me how to be my own hero 
APPENDIX B

SSCP PRESENTATION OUTLINE

1-Introduction

2-Who Am I?

-I love Rap Music "Soldat sans Contrat”

3- Where is Home?

-Where I am loved "Home"

-When and where I experience unconditional Love "Faceless love"

4- During my experience as an immigrant I was not blameless "Let's face it"

5-Story of 10-Year old Haitian survivor

-We are all interconnected "Nou Tout Haitien"

5- Conclusion

-What resonated most with you?

-What is Home for you?

-How will you help someone else feel at home?

-Why do people make places unwelcoming for others

-Which lines in each song struck a chord? 


\title{
APPENDIX C PARENTS' COVER LETTER AND PERMISSION FORMS
}

\author{
Human Subjects Research Review Committee \\ Research and Strategic Partnerships \\ http://www.pdx.edu/research/
}

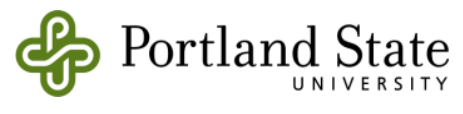

\section{COVER LETTER}

\section{Songs, Stories and their impact on Youth}

Dear Mr/Mrs. $X X X$ :

My name is Parfait Bassalé and I am a student at Portland State University. I am beginning a study on the positive impact of songs and stories on youth. The study is seeking to verify whether a song and story centered pedagogy is successful at increasing youth's ability to empathize with others. I am contacting you to request that you volunteer your classroom for this study. The learning outcomes of the workshop are tied to the Oregon State social studies standards and therefore fit within the state mandated curriculum. Several Social Studies teachers have been contacted randomly to participate in this study.

As part of the study, I am interested in your student's present disposition towards empathy, and hope that after the workshop that will exposed them to songs and stories designed to expand their perspectives, they will increase their ability to empathize. The results of the study will help us to better understand the efficacy of the workshop and ways in which it can be included within classrooms across America. If you decide to participate, you will volunteer one classroom period for me to come and conduct the workshop in your classroom, your students will be asked to fill out a consent form signed by their legal guardians, and they will also be asked to fill out a pre and post intervention survey assessing their dispositional empathy measures.

As a result of this study, your students may experience personal embarrassment as they fill out the surveys or feel challenged as they are exposed to the songs and stories presented in the workshop. However, I assure you that the content of the songs are totally appropriate and students are given the permission to remove themselves from the study at any point of the study.

No personal information will be collected for the sake of publication. Any names gathered through the consent forms will be kept safely in a locked cabinet and destroyed three years after the workshop.

Students may not receive any direct benefit from taking part in this study, but given the 
expected outcomes of the intervention, they are likely to receive an increase in their ability to empathize with others, engage in other-centered perspective taking when faced with discourse and/or disagreement.

Additionally they will be contributing in benefiting a generation of peace practitioners and teachers who want to use music in the classroom to teach empathy.

Participation is entirely voluntary. We hope that your students' decision to participate or not will not affect your relationship with them in any way. If you decide to volunteer your classroom in the study, and if your students decide to take part in, they may choose to withdraw at any time without penalty. Please keep a copy of this letter for your records.

If you have questions or concerns about your participation in this study, please feel free to contact me at 971-409-7841. If you have concerns about your rights as a research subject, please contact Research and Strategic Partnerships, Market Center Building $6^{\text {th }}$ floor, Portland State University, (503) 725-4288.

Sincerely,

Parfait Bassalé

Portland State University 
Human Subjects Research Review Committee Research and Strategic Partnerships http://www.pdx.edu/research/

\section{BE PART OF AN IMPORTANT PROJECT}

Music and its impact on youth

A student from Portland State University, Parfait Bassale is doing a Master thesis research study on how songs and stories affect youth. To do so, he will be coming to your classroom, will perform songs and tell stories about those songs.

\section{What Will I Have To Do?}

If you decide to take part in this project, we will ask you to fill out a 28 question survey before the day of the workshop and also after the presentation and You will also be asked to attend the presentation.

It will take you about 10 minutes to answer the questions. Your teacher will hand out the survey prior to the day of the workshop. You can fill it out at home using a pencil provided by Parfait. You can then return the survey to class the next day and turn it in at the same time your classmates are turning theirs in. If you choose to not participate, you can turn in a blank survey. This will ensure your privacy and none of your peers will know whether you are participating or not.

The questionnaire includes topics such as:

- How do you feel after watching movies?

- How do you feel when you read books?

\section{Are There Any Risks?}

These questions can seem personal at times. You do not have to take part in this study. But if you do agree to take part, you may feel uncomfortable or slightly embarrassed because of some of the questions we ask. . During the workshop if you don't want to go on, you can stop at any time. If you are upset after filling out the questionnaire or when attending the workshop and need to talk with someone, you can call and/or talk to Parfait Bassale at the PSU Conflict Resolution Department; he's the person leading the project in Portland.

\section{What Will I Get In Return?}

- Knowing you are helping others 
Many people feel good about helping others. We can learn so much from you about the effect of songs on young people like you. It will help teachers across the world with including music in the classrooms.

What Are You Doing To Protect Me?

Your privacy is very important to us. We have done many things to protect you:

We won't tell anyone if you take part in this study or not

You will not be required to give your name on the questionnaire.

This signed informed consent will not be linked to your questionnaire.

What you tell us will be kept private.

Only Parfait Bassalé, the researcher, will know what you say. No one at your school and classroom will know what you answer.

Your name and other personal information, which we need in order to keep track of who we received consent from, will be kept in a locked file cabinet or in a locked file on the computer so that no one other than the research staff will be able to see it. For example, this form (which has your name on it) will be kept in a locked file cabinet.

When we write or talk about what we learned in this study, we will leave things out so no one will be able to tell who we are talking about.

You can attend the workshop even if you decide to not fill out the survey. You can return blank surveys if you choose to not participate.

When you fill-out the survey in class after the workshop, everyone will be asked to focus on their survey and not to look at someone else's survey. This will help ensure your privacy. Parfait Bassalé and your teacher will oversee this process to make sure you feel safe.

\section{Any Questions?}

If you have any questions about this study, this form, or the interview, you can talk to the person leading the project in Portland. (Parfait Bassale 971-409-7841). You can also contact the Chair of the Human Subjects Committee of Portland State University about your rights as a research participant (someone who takes part in a study). Hours are 9:00 a.m. to 5:00 p.m. The office is located at Portland State University, Market Center Building, $6^{\text {th }}$ floor, Portland, OR 97201. The telephone number is (503) 725-4288

\section{If I Sign, What Does It Mean?}

This is a consent form. Your signature below means that:

You have read and you understand what this form says.

You are willing to take part in the study by filling out the survey questionnaire, participating in the workshop and filling out the survey at the end of the workshop. You know that you do not have to take part in this study. And even if you agree, you can change your mind and stop at any time. No problem

If you found out about this study at your school you know that taking part in this study has nothing to do with the education you get there. If you agree to take part or if you say no, they won't know and it won't matter. They will treat you the same.

You will get a copy of this form to keep for yourself. 
Participant Signature
Date Participant name, printed

Interviewer/Witness/Legal Guardian Signature Date Interviewer/Witness/Legal Guardian name, printed $* * *$ 


\section{PARENTAL PERMISSION}

Research Project: Music, stories and their impact on youth

Your child is invited to participate in a research study conducted by Parfait Bassale from Portland State University, Department of Conflict Resolution. The researcher hopes to learn about the impact of songs and stories on today's youth. The study is designed to discover whether positive lyrics and narratives yield a positive impact of listeners. The study is being conducted in partial fulfillment of the requirements for a master's degree and is under the supervision of Dr. Rachel Cunliffe a faculty in the department of Conflict resolution at PSU. Your child was selected as a possible participant in this study because he is a student of MR/Mrs XXX a social studies teacher at XXX School who volunteered his/her classroom for the study.

If you decide to let your child participate, he/she will be asked to fill out a 28 item survey questionnaire which will take him/her 10 minutes to complete. He/she will also participate in a one hour workshop in which he/she will be exposed to songs and stories that inspired the writing of those songs. The workshop will be conducted in the classroom and after he/she will be asked to fill out a final survey (same questionnaire) in order to assess the impact of the workshop.

While participating in this study, it is possible your child might feel uncomfortable and/or challenged by the questions and/or stories described in the songs. He/she will be allowed to stop his/her participation if such is the case. However there are no known records of the survey and songs causing pain, hurt or anger.

Your child may not receive any direct benefit from taking part in this study, but the study may help change the way schools use songs and stories in the classrooms across America.

Any information that is obtained in connection with this study and that can be linked to your child or identify your child will be kept confidential. The personal information (Name) captured in the consent forms will be locked in a file cabinet and destroyed 3 years after the workshop is conducted (This is required by the human subjects protection Bureau). Names will not be included in the final publication of the results of the study.

Your child's participation is voluntary. He/she does not have to take part in this study, and it will not affect his/her course grade or relationship with XXX . You may also withdraw your permission for your child to participate from this study at any time without affecting his/her course grade or relationship with XXX. Likewise, your child may withdraw his/her assent at any time without affecting his/her course grade or relationship with $\mathbf{X X X}$. 
If you have questions or concerns about your child's participation in this study, contact Parfait Bassalé at parfait@parfaitonline.com or (871) 409 7841. If you have concerns about your child's rights as a research subject, please contact Research and Strategic Partnerships, Market Center Building $6^{\text {th }}$ floor, Portland State University, (503) 725-4288.

Your signature indicates that you have read and understand the above information and agree to let your child take part in this study. The researcher should provide you with a copy of this form for your own records.

Signature

Date

\section{Print name}




\section{APPENDIX D \\ SSCP, HISTORY, DESIGN, AND PROCEDURE}

\section{History/Context}

In 2001 during my undergraduate studies at Portland State University, I was awarded the ICSP scholarship. ICSP is a state funded program that financially supports international students in return of community service. As a recipient of the scholarship, I was required to go into classrooms and to share about my culture, and my experiences growing up in Africa.

The first years, my presentations comprised biographical elements, informational pieces and myth busters. Initially my goals were to get students participation, to trigger a change in perspective and to move students towards action. To do so, I shared personal stories, answered questions and debunked stereotypes about Africa. Over the months and years I paid close attention to the way I phrased questions, students' responses and class dynamics. Threads of best practices for my desired outcomes began to emerge. These could be grouped into two categories.

\section{Information that informed Workshop procedure}

This approach has been informed by nearly 10 years of action research.

Students enjoy personal stories. I noticed that students looked more interested and captivated by personal stories than abstract and/or conceptual narratives. Participation increased in classrooms where I shared more about myself and some specific stories of me growing up as a teenager. 
Students expressed their engagement by the amount of eye contacts; hands raised and follow up questions.

Students respect and respond to music. Though it is hard to quantify, I noticed a sharp difference in how I was received in the classrooms when I started coming in with a musical instrument. There was a combination of excitement, and amazement. These two emotions helped command student's attention during sessions. It is as if with an instrument, I earned their respect and the right to speak into their lives.

Spring 2008 I was conducting a presentation for a youth empowerment organization REAP. The event was titled "I AM" and was hosted at Beaverton Middle School. I was scheduled for two consecutive sessions. My presentations comprised 3 songs and narration parts. For the first class I lectured the first half and saved the performances piece for the end. There was a group of teenagers who were turbulent and distracting all throughout the first half of the presentation. When I started performing the songs (one of them was a rap song) their countenance changed and they became more attentive. At the end of the presentation they approached me and expressed their appreciation of the workshop and the things I had to say.

Conscious of this experience, I decided to switch things up for the second period. I started the presentation with singing and ended with the lecture piece. This time around, I had no disciplinary issues. This could have been due to a number of things such as a more behaved audience. However, multiple times after this experience, I have noticed that by beginning the presentation with a performance, the energies of the rowdiest in the audience get channeled towards participation rather than distraction. 
APPENDIX E

HUMAN SUBJECT APPROVAL

\section{Portland State}

\section{PortlandStateUniversityHSRRCMemarandum}

\section{To: Parfait Bassalé}

From: Mary Oschwald, Chair, HSRRC 2012

Date: June 5, 2012

Re: Your HSRRC application titled, "Music and Conflict Resolution: Under what conditions does a story and song centered workshop enhance empathy" (HSRRC Proposal \#122141)

In accordance with your request, the Human Subjects Research Review Committee has reviewed your proposal referenced above for compliance with DHHS policies and regulations covering the protection of human subjects. The committee is satisfied that your provisions for protecting the rights and welfare of all subjects participating in the research are adequate, and your project is approved.

Please note the following requirements:

Changes to Protocol: Any changes in the proposed study, whether to procedures, survey instruments, consent forms or cover letters, must be outlined and submitted to the Chair of the HSRRC immediately. The proposed changes cannot be implemented before they have been reviewed and approved by the Committee.

Continuing Review: This approval will expire 06/05/2013, one year from the approval date.. It is the investigator's responsibility to ensure that a Continuing Review Report (available in ORSP) of the status of the project is submitted to the HSRRC approximately two months before the expiration date, and that approval of the study is kept current.

Adverse Reactions: If any adverse reactions occur as a result of this study, you are required to notify the Chair of the HSRRC immediately. If the problem is serious, approval may be withdrawn pending an investigation by the Committee. 
Completion of Study: Please notify the Chair of the Human Subjects Research Review Committee (campus mail code ORSP) as soon as your research has been completed. Study records, including protocols and signed consent forms for each participant, must be kept by the investigator in a secure location for three years following completion of the study.

If you have questions or concerns, please contact the HSRRC in the Office of Research and Strategic Partnerships, Market Center Building, Suite 620, 1600 SW Fourth Ave, Portland OR 97207 (503)725-2243.

cc: Brenda Fugate 